\title{
Streaming-potential coefficient of reservoir rock: A theoretical model
}

\author{
Paul W. J. Glover ${ }^{1}$, Emilie Walker², and Matthew D. Jackson ${ }^{3}$
}

\begin{abstract}
The streaming potential is that electrical potential which develops when an ionic fluid flows through the pores of a rock. It is an old concept that is recently being applied in many fields from monitoring water fronts in oil reservoirs to understanding the mechanisms behind synthetic earthquakes. We have carried out fundamental theoretical modeling of the streaming-potential coefficient as a function of pore fluid salinity, $\mathrm{pH}$, and temperature by modifying the HS equation for use with porous rocks and using input parameters from established fundamental theory (the Debye screening length, the Stern-plane potential, the zeta potential, and the surface conductance). The model also requires the density, electrical conductivity, relative electric permittivity and dynamic viscosity of the bulk fluid, for which empirical models are used so that the temperature of the model may be varied. These parameters are then combined with parameters
\end{abstract}

that describe the rock microstructure. The resulting theoretical values have been compared with a compilation of data for siliceous materials comprising 290 streaming-potential coefficient measurements and 269 zeta-potential measurements obtained experimentally for 17 matrix-fluid combinations (e.g., sandstone saturated with $\mathrm{KCl}$ ), using data from 29 publications. The theoretical model was found to ably describe the main features of the data, whether taken together or on a sample by sample basis. The low-salinity regime was found to be controlled by surface conduction and rock microstructure, and was sensitive to changes in porosity, cementation exponent, formation factor, grain size, pore size and pore throat size as well as specific surface conductivity. The high-salinity regime was found to be subject to a zeta-potential offset that allows the streaming-potential coefficient to remain significant even as the saturation limit is approached.

\section{INTRODUCTION}

A fluid flowing through a porous rock moves ions in such a way that an electrical potential difference is created (the streaming potential), and an electrical current flows to restore the balance (the streaming current) (Pride, 1994). If the theory that describes the mechanism were known, it would be possible to calculate the permeability of a rock from an electrical measurement without recourse to empirical data fitting as in Glover et al. (2006). Furthermore, because electrical parameters can be measured remotely by selfpotential (Ishido and Mizutani, 1981; Antraygues and Aubert, 1993; Revil et al., 2003) (magneto-)telluric (Svetov et al., 1997; Aizawa et al., 2005; Ingham et al., 2009) and GPR techniques (Dupuis et al., 2007), these data may be used to calculate regional or local fluid flow (Perrier et al., 1999; Sailhac and Marquis,
2001; Trique et al., 2002; Darnet and Marquis, 2004), or even caused by the redox conditions inside the contaminant plume in a groundwater system (Naudet et al., 2004).

Already, self-potential measurements have been used to map (1) the convective flow of fluids around volcanoes using electrokinetic coupling (e.g., Revil et al., 2003; Aizawa et al., 2005), (2) the encroachment of water into a hydrocarbon reservoir (Saunders et al., 2008; Jaafar et al., 2009), and (3) in the characterization of subsurface aquifers (Dupuis and Butler, 2006; Dupuis et al., 2009). The same approach may be used to monitor the depletion of a waterdriven reservoir (Fagerlund and Heinson, 2003; Titov et al., 2005; Revil et al, 2003), in geothermal reservoirs (Corwin et al, 1981; Darnet et al., 2004) or the sudden flow of water into a previously dormant but potentially seismically active fault prior to an earthquake (Mizutani et al., 1976; Di Maio and Patella, 1991; Probstein

Manuscript received by the Editor 27 September 2011; published online 7 March 2012.

${ }^{1}$ Formerly Université Laval, Department of Geology and Engineering Geology, Québec, Canada; presently University of Leeds, School of Earth and Environment, Leeds, U. K. E-mail: paglover@ggl.ulaval.ca.

${ }^{2}$ Université Laval, Department of Geology and Engineering Geology, Québec, Canada. E-mail: walker.emilie@gmail.com.

${ }^{3}$ Imperial College London, Department of Earth Science and Engineering, London, U. K. E-mail: matthew.jackson@icst.ac.uk. (C) 2012 Society of Exploration Geophysicists. All rights reserved. 
and Hicks, 1993; Ishido and Pritchett, 1999). Applications are not necessarily restricted to measurement and monitoring. There have been studies, for example, involving the electrokinetic remediation of contaminated soil (e.g., Shapiro and Probstein, 1993). Many of these applications have direct and useful applications in the hydrocarbon industry, and some are applicable downhole.

Because the passage of a seismic wavelet implies local changes in fluid pressures and consequent fluid flow, the transport of seismoacoustic energy through a rock is linked to fluid flow (Pride, 1994). Hence, we may extend the electrokinetic phenomenon to incorporate seismoelectrokinetic coupling. It is possible, in principle to perturb a layered earth with a seismic pulse, then to measure the resulting electrical signals as a function of offset (e.g., Thompson and Gist, 1993; Haines et al., 2007). The so-called seismoelectric method relies on differences in the seismoelectrokinetic coupling at interfaces in the subsurface, and has recently been used to successfully image the vadose zone of a sand aquifer (Dupuis et al., 2007).

The fluid-flow-electrical coupling has its origins in the electrical double layer (EDL) that is formed at the interface between the pore fluid and the rock matrix. A full description of the mechanism and a diagram of the EDL can be found in (Glover and Jackson, 2010).

The streaming potential of capillary tubes is known to be governed by the Helmholtz-Smoluchowski (HS) equation (e.g., Overbeek, 1952; Hunter, 1981; Maineult et al., 2004; Saunders et al., 2008), which is given in its simplest form by

$$
C_{s}=\frac{\Delta V}{\Delta P}=\frac{\varepsilon_{r} \varepsilon_{o} \zeta}{\eta_{f} \sigma_{f}^{*}}
$$

where the streaming potential $C_{s}$ (in $\mathrm{V} / \mathrm{m}$ ) is the ratio of the measured streaming potential $\Delta V$ (in $\mathrm{V}$ ) to the applied fluid pressure difference $\Delta P$ (in $P a$ ) that drives the fluid through the capillary tube. This value depends upon the electric permittivity of the pore fluid $\varepsilon_{f}=\varepsilon_{r} \varepsilon_{o}$ (in $\left.\mathrm{F} / \mathrm{m}\right), \varepsilon_{r}$ is the relative permittivity of the pore fluid (unitless), $\varepsilon_{o}$ is the electric permittivity of free space $\left(\approx 8.854 \times 10^{-12} \mathrm{~F} / \mathrm{m}\right)$, the dynamic viscosity of the pore fluid $\eta_{f}$ (in Pa.s), the pore fluid electrical conductivity $\sigma_{f}^{*}$ (in $\mathrm{S} / \mathrm{m}$ ), and the zeta potential $\zeta$ (in V). The zeta potential is the electric potential on the shear plane when a part of the diffuse layer is transported by fluid flow.

Equation 1 is commonly applied to porous media including rocks even though it has never been validated for these media because there exists no independent measurement of the zeta potential for complex porous media. As far as we know, there has not even been a comparison of a compilation of streaming-potential coefficient data for rocks with its value derived from the electrical and electro-kinetic theory of porous media, even though most of the theoretical tools required have been available since 1998 (e.g., Revil and Glover, 1997; Revil et al., 1998). This paper carries out the required fundamental theoretical modeling of the streamingpotential coefficient as a function of pore fluid concentration, $\mathrm{pH}$, and temperature, and then compares the theoretical results with a compilation of streaming-potential coefficient data when taken together or on a sample by sample basis.

The approach used in this work is a combination of fundamental theory and the use of empirical relationships. Theoretical models have been used for the heart of the model, i.e., to calculate the Debye screening length, Stern plane potential, zeta potential, surface conductance, and streaming-potential coefficient of the rock.
Empirical relationships have been used to allow certain of the model's input parameters to vary as a function of temperature and fluid salinity instead of using input data from tables; these are the density, electrical conductivity, dynamic viscosity, and relative electric permittivity of the bulk fluid. In parallel with the approach of other researchers, we have initially treated dielectric saturation (Pride and Morgan, 1991) and viscoelectric effects (Lyklema and Overbeek, 1961; Hunter, 1966; Pride and Morgan, 1991) as negligible, and justify the choice in the section below, entitled Theoretical Development.

The fluid conductivity in equation 1 has contributions from the bulk fluid and surface conduction. The latter depends both on the surface conductance and the microstructural properties of the rock (porosity, cementation exponent, grain size, etc.) as discussed in detail in Glover and Déry (2010). Consequently, equation 1 can be rewritten as (Morgan et al., 1989)

$$
C_{s}=\frac{\Delta V}{\Delta P}=\frac{\varepsilon_{r} \varepsilon_{o} \zeta}{\eta_{f}\left(\sigma_{f}+\frac{2 \Sigma_{s}}{\Lambda}\right)},
$$

where $\Sigma_{s}$ is the specific surface conductance (in $\mathrm{S}$ ) and $\Lambda$ is a length scale characteristic of the pore microstructure (in $\mathrm{m}$ ) introduced by Johnson et al. (1987). In this paper we follow the approach of Glover and Déry (2010) by substituting the relationship of Revil and Cathless (1999) for the characteristic length scale $(\Lambda=d /(3(F-1)))$ into equation 2 to obtain an equation for the streaming-potential coefficient in terms of the mean grain diameter and formation factor of the rock giving equation 4 of Glover and Déry (2010),

$$
C_{s}=\frac{\Delta V}{\Delta P}=\frac{d \varepsilon_{f} \zeta}{\eta_{f}\left(d \sigma_{f}+6 \Sigma_{s}(F-1)\right)},
$$

where $d$ is the mean grain diameter (in m) and $F=\phi^{-m}$ is the formation factor of the rock. It is worthwhile noting that we have chosen to work with grain diameter in this modeling. However, other equations in Glover and Déry (2010) allow the modeling to be carried out as a function of pore radius or pore throat radius if one wishes.

The zeta potential and surface conductance have been calculated according to the model of Revil and Glover (1997), Revil et al. (1998) and Revil et al. (1999a). Although the modeling has been carried out as a function of bulk fluid $\mathrm{pH}$, it should be noted that the $\mathrm{pH}$ of the solution decreases in the diffuse layer as one approaches the mineral surface. Because the position of the shear plane is very close to the surface (a distance of about $2.4 \times 10^{-10} \mathrm{~m}$ according to Revil and Glover (1997) [see Figure 8 of that paper and the associated text on page 1771]), it is possible that the zeta potential would be significantly altered by the perturbation of the $\mathrm{pH}$ close to the mineral surface. So, there is the question of whether the bulk fluid property is the most appropriate one to use, or whether an adjusted $\mathrm{pH}$ value should be used in the calculation of the zeta potential. However, we have no mechanism for making this adjustment because the surface conduction theory of Revil and Glover (1997) and Revil et al. (1999a) only accounts for pH variation in the bulk fluid. We are forced, therefore, to make the unsupported assumption that the second-order $\mathrm{pH}$ effects close to the surface including their effect on the zeta potential are negligible for most pore fluid salinities. 
This paper has four remaining sections. In the first we review the existing streaming-potential coefficient and zeta-potential data. In the second we describe a theoretical method for calculating the Stern-plane potential, zeta potential, surface conductance, and streaming-potential coefficient of reservoir rocks and other porous media. The third section examines the reasonable ranges of the various model parameters in the light of electrochemical research. The fourth section compares the results of the theoretical model with the experimental data. We originally thought to include a further section which would have examined the sensitivity of the model to changes in each parameter using the fits available from the experimental data as a base case. However, it has become clear that such a combined paper would be extremely large, with an especially large number of figures. Consequently, we will publish the parametric sensitivity analysis in a subsequent communication.

\section{EXPERIMENTAL DATA}

Figures 1 and 2 show a compilation of streaming-potential coefficient and zeta-potential data based on that made by Vinogradov et al. (2010) that represents the best compilation of such data available in the public domain. This data set includes 290 determinations of streaming-potential coefficient for 10 matrix-fluid combinations from 18 publications, and 269 determinations of zeta potential for 11 matrix-fluid combinations from 16 publications. We consider a matrix-fluid combination to be a generic combination of a mineral or artificial porous substrate saturated with a fluid irrespective of the source of the matrix material or the temperature, $\mathrm{pH}$ or salinity of the fluid. Examples of matrix-fluid combinations are (1) basalt and $\mathrm{KCl}$, (2) limestone with $\mathrm{NaCl}$, or (3) quartz glass beads with $\mathrm{NaCl}$. The data in most of the figures in this paper have been classified accordingly to enable the information to be presented in as clear a fashion as possible. Only four samples are named explicitly in the figures (i.e., the St. Bees, Fontainebleau, and Stainton sandstones measured by Vinogradov et al. (2010) and Jaafar et al. (2009)).

\section{Streaming-potential coefficient}

Figure 1 shows that the streaming-potential data are fairly wide spread especially at low salinity (given that both axes are logarithmic). In addition, there seems to be a tendency for the streamingpotential coupling curves to flatten out at low salinity. This effect is seen best in the Li et al. (1995) data. We hypothesize that the spread in the data at low salinity results from differences in the surface conduction between the samples. Since the surface conduction term in equation 3 is associated with the parameters that control the microstructure of the rock (i.e., cementation exponent, grain size, porosity, formation factor), we expect the low-salinity behavior to be affected by those microstructural parameters. Different rocks, with different microstructures would then have different low-salinity streaming-potential coefficient curves, leading to the observed spread of data in the global data set.

Another possible cause of the spread in Figure 1 is that all the data were not measured with a pore fluid of the same $\mathrm{pH}$, but varied from about $\mathrm{pH}=5.5$ to $\mathrm{pH}=11$ (see Table 1 ). We show later that while variation of the $\mathrm{pH}$ in this range is not sufficient to cause all the variability seen in Figure 1, it is sufficient to lead to the variability of approximately one order of magnitude seen in the figure for pore fluid salinities greater than about $10^{-2} \mathrm{~mol} / \mathrm{L}$. The sensitivity of the streaming-potential coefficient to $\mathrm{pH}$ has already been noted by Jouniaux et al. (2000), who took account of both surface conduction and $\mathrm{pH}$ to reduce the spread of their measurements.

Figure 1 also shows two curves that are the result of empirical fittings. Pride and Morgan (1991) discovered that the experimental determinations of zeta potential at medium and low salinities available to them were all well described by the relationship $\zeta(\mathrm{mV})=a+b \log \left(C_{f}\right)$, where the two parameters varied over a small range for the five datasets to which they had access. A relationship of this form is also predicted from the double layer theory described by Revil et al. (1999a). Jaafar et al. (2009) apply this generic relationship to the larger database of zeta-potential measurements to which they had access, and arrived at the empirical relationship $\zeta(\mathrm{mV})=-6.43+20.85 \log \left(C_{f}\right)$. This equation has been used with (1) equation 1 (2) the relative permittivity $\varepsilon_{r}$ calculated using equation 5 below (3) the dynamic viscosity $\eta_{f}$ of the pore fluid calculated using equation 6 below, and (4) the pore fluid conductivity $\sigma_{f}$ calculated using equation 4 below, to calculate the streaming-potential coefficient as a function of pore fluid salinity. The result is shown as the dashed line in Figure 1.

Prior to the work of Vinogradov et al. (2010) and Jaafar et al. (2009) there were two interpretations of this curve at high salinity.

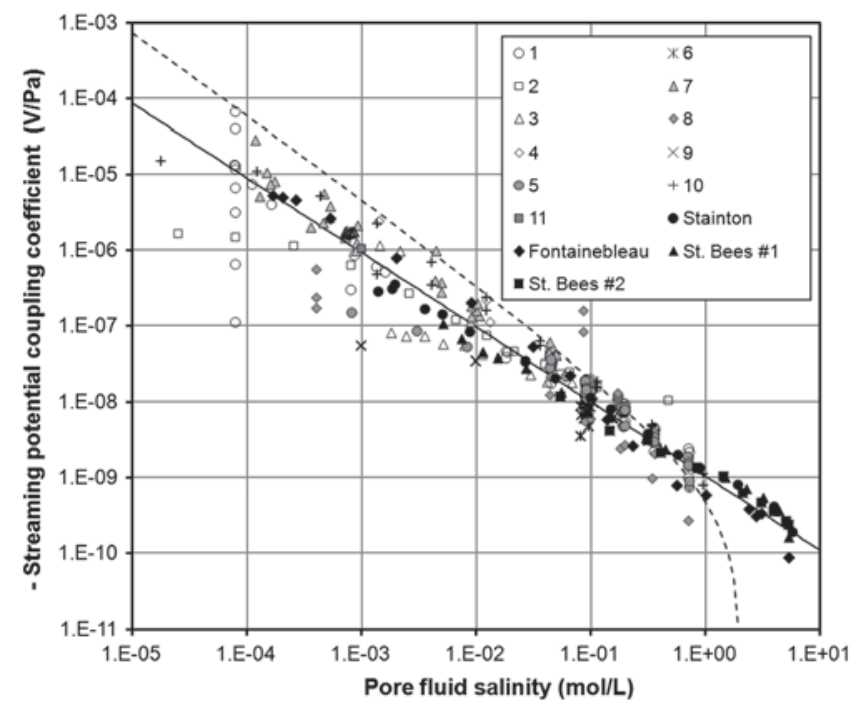

Figure 1. A compilation of 290 experimentally measured values of the streaming-potential coefficient as a function of pore fluid salinity. All values are negative. [1] Sandstone with $\mathrm{NaCl}$ (Sprunt et al., 1994; Jouniaux and Pozzi, 1995, 1997; Li et al., 1995; Jiang et al., 1998; Pengra et al., 1999); [2] sandstone with KCl (Alkafeef and Alajmi, 2006); [3] sand with $\mathrm{NaCl}$ (Guichet et al., 2003; Block and Harris, 2006); [4] granite with $\mathrm{NaCl}$ (Morgan et al., 1989); [5] glass with $\mathrm{NaCl}$ (Pengra et al., 1999; Block and Harris, 2006); [6] zeolitized tuffs with $\mathrm{NaCl}$ (Revil, 2002; Revil et al., 2002); [7] basalt with $\mathrm{NaCl}$ (Revil et al., 2003); [8] limestone and carbonate with $\mathrm{NaCl}$ (Sprunt et al., 1994; Li et al., 1995; Jouniaux and Pozzi, 1995a; Pengra et al., 1999; Revil and Cerepi, 2004); [9] granite with $\mathrm{KCl}$ (Tosha et al., 2003); [10] silica nano-channel with $\mathrm{KCl}$ (van der Heyden, 2006); [11] Ottawa sand (Tardif et al., 2010). The named samples are from Vinogradov et al. (2010) and Jaafar et al. (2009). Temperature $20^{\circ} \mathrm{C}-25^{\circ} \mathrm{C}$. $\mathrm{pH} 5-9$ for all samples except $\mathrm{pH} 8-11$ for limestones. The dashed line is the coefficient calculated from the general empirical regression of zeta potential by Pride and Morgan (1991), used with all the data in Jaafar et al. (2009) except that by the authors $\zeta(\mathrm{mV})=-6.43+20.85 \log \left(C_{f}\right)$, and the solid line is an empirical fit to the Vinogradov et al. (2010) data $C_{s}=1.039 \times$ $10^{-9} C_{f}^{-0.9574}, R^{2}=0.9829$, made by us. 


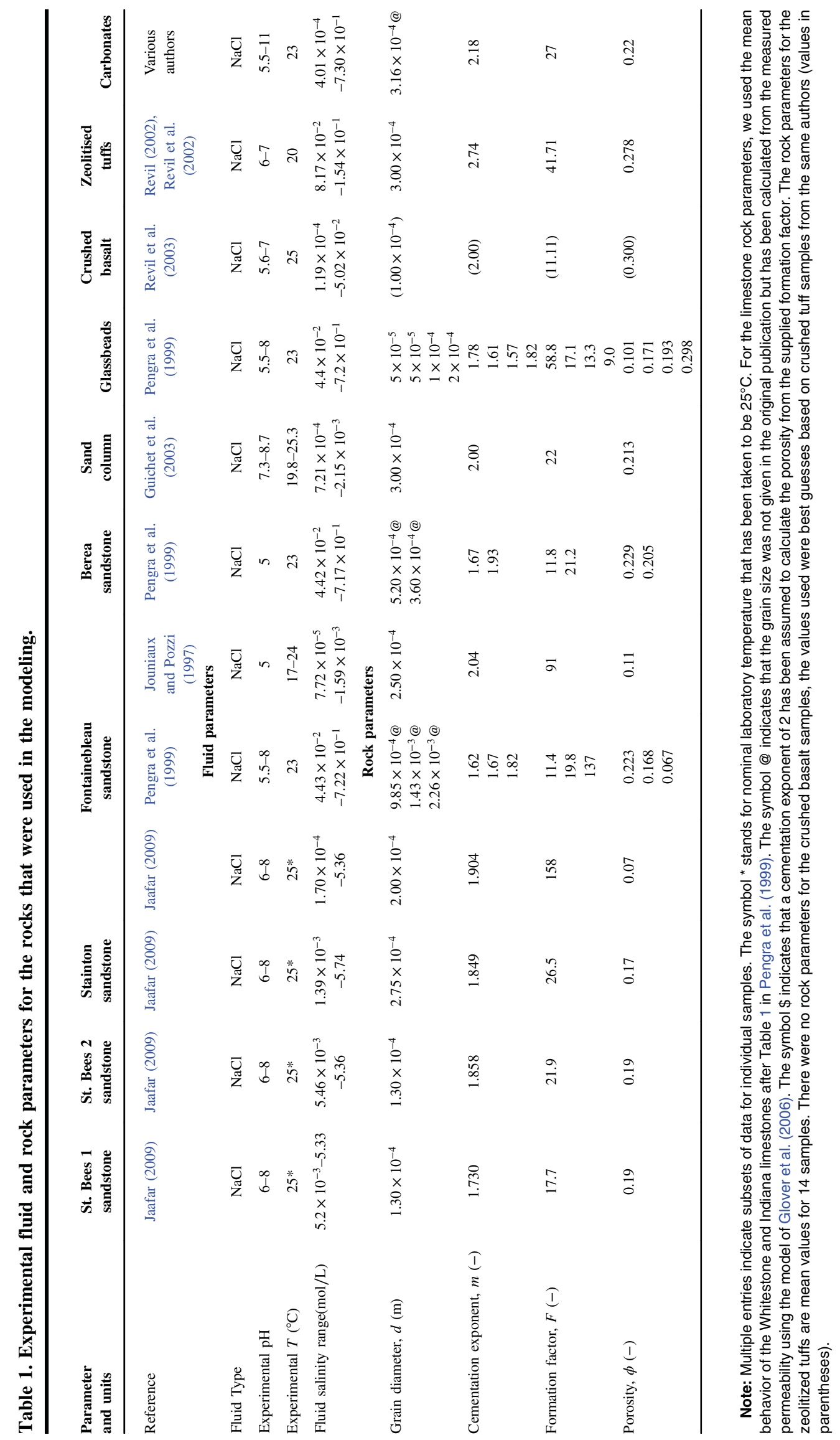


The first was that there would be positive streaming potentials at $C_{f}>2 \mathrm{~mol} / \mathrm{L}$. The second was that the equation was not valid at high salinity. Because there were no experimental measurements for $C_{f}>1 \mathrm{~mol} / \mathrm{L}$, it was not known if either of the two interpretations was correct. Vinogradov et al. (2010) and Jaafar et al. (2009) report high quality streaming-potential coefficient measurements at very high salinity, showing that there were no positive streaming coefficients, and that the Pride and Morgan (1991) equation was not valid at high salinity.

We have carried out an empirical fitting to the measurements as a function of salinity on four sandstone samples that comprise Vinogradov et al. (2010) data, and arrive at $C_{s}=-1.039 \times 10^{-9} C_{f}^{-0.9574}$, $R^{2}=0.9829$, which is shown as the solid line in Figure 1. In addition, recently Allègre et al. (2010) have provided an empirical fit to their data as $C_{s}=-1.1 \times 10^{-8} / \sigma_{f}$. Although our fitting is expressed as a function of salinity and that of Allègre et al. (2010) is in terms of fluid conductivity, they are almost equivalent. This can be shown by setting the two equations equal, giving the approximation $\sigma_{f} \approx 10 C_{f}$, which agrees extremely well with the Sen and Goode (1992a; 1992b) model for fluid conductivity of a $\mathrm{NaCl}$ solution as a function of salinity in the ranges $10^{-6}<C_{f}<1 \mathrm{~mol} / \mathrm{L}$ and $15<T<25^{\circ} \mathrm{C}$. This observation implies that the two empirical fits above are almost identical, despite being derived from different datasets; an observation that shows consistency in both sets of experimental measurement.

\section{Zeta potential}

It should be noted that all of the zeta-potential data used by this paper and gathered by Vinogradov et al. (2010) and Jaafar et al. (2009) and ourselves are calculated from experimental measurements of the streaming-potential coefficient using knowledge of the electrical conductivity, viscosity, and dielectric permittivity of the pore fluid that has been obtained experimentally. Such an approach is problematic because there are fundamental difficulties in knowing the appropriate values of electrical conductivity, viscosity, and electric permittivity of the pore fluid to take. Glover and Déry (2010) discuss the problems associated with surface conduction that leads to streaming-potential coefficients being controlled by the microstructure of the rock. They also discuss the choice of electric permittivity and viscosity. Hence, zeta potentials that are derived from streaming-potential coefficient measurements should always be considered together with the parameters that were used to calculate them.

This paper seeks to calculate the zeta potential and hence the streaming-potential coefficient theoretically. Such an approach has the potential for producing a zeta potential without the difficulties encountered in the experimental approach.

Figure 2 shows that the zeta-potential data are also widely spread, but seem to follow the trend that the zeta potential becomes smaller logarithmically, but remains negative as the salinity increases. The work of Jaafar et al. (Vinogradov et al., 2010; Jaafar et al., 2009) seems to indicate that there is a zeta-potential threshold at higher salinities $(>0.4 \mathrm{~mol} / \mathrm{L})$, which they tentatively ascribe to charge density saturation in the EDL when the Debye screening length is of the same magnitude as the size of a hydrated $\mathrm{Na}^{+}$cation $(\sim 4.7 \times 10 \mathrm{~m})$ (Jaafar et al., 2009).

We show later from the theoretical model that the zeta potential is independent of rock microstructure and surface conduction. Rather, it depends upon the physical chemistry of the EDL, and in particular on the $\mathrm{pH}$, the surface site density, the binding constant for cation (sodium) adsorption on quartz, and the disassociation constant for dehydrogenization of silanol surface sites. Providing that these parameters are the same for all the data in Figure 2, the observed scatter in the zeta-potential data that is particularly pronounced at low salinity can only be attributed to errors in its derivation. Because the derivation of zeta potential from streaming-potential coefficient measurements requires the accurate measurement of the effective conductivity of the pore fluid (i.e., the bulk pore fluid plus the contribution from the surface conduction), it may be that some of the zeta-potential data have a built in systematic error. However, the apparent threshold in zeta potential cannot be explained by such a systematic error, because any error present would be negligible at high salinity where the apparent threshold occurs.

The most likely cause of the low-salinity spread in the data in Figure 2 is variation in the $\mathrm{pH}$ of the pore fluids. Often the $\mathrm{pH}$ of the effluent pore fluid was not measured or not reported. It is perfectly possible to have a fluid $\mathrm{pH}$ in the range $\mathrm{pH}=6$ to $\mathrm{pH}=8$. We show later from the theoretical model that variation of $\mathrm{pH}$ in this range does have a large effect on the zeta potential, especially at low salinity.

\section{THEORETICAL DEVELOPMENT}

It is possible to calculate the streaming-potential coefficient of reservoir rocks thanks to theoretical developments that began in 1997 (Revil and Glover, 1997, 1998; Revil et al., 1999a) and have been supplemented and modified until recently (Glover and Déry, 2010; Walker and Glover, 2010). Here we combine them to provide

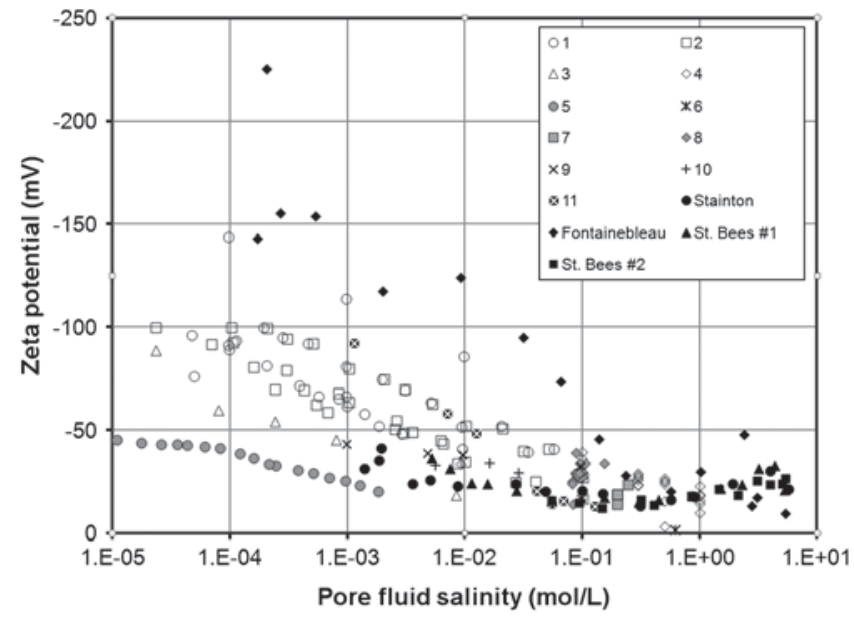

Figure 2. A compilation of 269 experimentally measured values of the zeta-potential coefficient as a function of pore-fluid salinity. All values are negative. [1] Quartz with $\mathrm{NaCl}$ (Pride and Morgan, 1991); [2] silica with $\mathrm{NaCl}$ (Gaudin and Fuerstenau, 1955; Li and de Bruyn, 1966; Kirby and Hasselbrink, 2004); [3] glass beads with $\mathrm{NaCl}$ (Bolève et al., 2007); [4] clay minerals with $\mathrm{NaCl}$ (Kosmulski and Dahlsten, 2006; Avena and De Pauli, 1998); [5] sandstone with $\mathrm{KCl}$ (Lorne et al., 1999); [6] quartz with $\mathrm{NaCl}$ (Kosmulski et al., 2002); [7] kaolin coated sandstone with $\mathrm{NaCl}$ (Pengra et al., 1999); [8] tuff samples containing clays and zeolites (Revil 2002; Revil et al., 2002); [9] kaolinite with NaCl (Poirier and Cases., 1985); [10] mica with $\mathrm{NaCl}$ (Will and Nover, 1986); [11] sandstone with $\mathrm{NaCl}$ (Alkafeef and Alajmi., 2006);. The named samples are from Vinogradov et al. (2010) and Jaafar et al. (2009). Temperature $20^{\circ} \mathrm{C}-25^{\circ} \mathrm{C}$; pH $5-9$ for all samples except limestones, $\mathrm{pH}$ 8-11 for limestones. 
a model for calculating the streaming-potential coefficient as a function of 18 fundamental parameters including temperature, pore fluid concentration, and $\mathrm{pH}$, as well as rock parameters such as porosity, grain size, pore size, and formation factor.

Examination of equation 2 shows that to calculate the streamingpotential coefficient we need to obtain (1) the zeta potential, (2) the electrical permittivity of the pore fluid, (3) the viscosity of the pore fluid, (4) the bulk fluid conductivity, (5) the surface conductance, and (6) some measure of the characteristic length scale of the pores as discussed in Walker and Glover (2010). Here we use the grain size and equation 4 in Glover and Déry (2010), but one might equally well use the pore radius or the pore throat radius together with the respective equation in Glover and Déry (2010) instead.

The calculation method follows the following steps:

1) calculation of the pore fluid conductivity as a function of temperature and pore fluid concentration using the empirical model of Sen and Goode (1992a, 1992b)

2) calculation of the pore fluid relative permittivity as a function of temperature and pore fluid concentration using the empirical model of Gary Olhoeft (unpublished note, 1980) (Revil et al., 1999b)

3) calculation of the density of the pore fluid as a function of salinity and temperature

4) calculation of the molality of the pore fluid as a function of salinity and temperature

5) calculation of the pore fluid viscosity as a function of temperature and pore fluid molality using the empirical model of Phillips et al. (1978)

6) definition of the physical chemistry of the double layer

7) calculation or definition of the $\mathrm{pH}$ of the solution (please see Appendix A)

8) calculation of the Debye screening length and the shear plane distance (Revil and Glover, 1997, 1998; Revil et al., 1999a)

9) calculation of the Stern-plane potential (Revil and Glover, 1997, 1998; Revil et al., 1999a)

10) calculation of the zeta potential (Revil and Glover, 1997, 1998; Revil et al., 1999a)

11) calculation of the surface conductance (Revil and Glover, 1997, 1998; Revil et al., 1999a)

12) use of one of the forms of the modified HelmholtzSmoluchowski equation given in Glover and Déry (2010), to finally calculate the streaming-potential coefficient as a function of either (1) grain size, (2) pore size, or (3) pore throat size

There are a large number of input parameters in the model. Not all of them have a large impact upon the final streaming-potential coefficient values, and this will be described in more detail in a further scientific contribution. The input parameters fall into five groups:

1) fundamental constants (e.g., Boltzmann's constant and Avogadro's number)

2) environmental conditions (e.g., temperature)

3) fluid parameters (e.g., solute concentration, $\mathrm{pH}, p K_{w}, p K_{1}$ and $p K_{2}$ )

4) rock microstructure parameters (e.g., formation factor, cementation exponent, porosity, grain size, etc.)

5) rock-fluid interface parameters, i.e., the electro-chemical parameters associated with surface adsorption reactions (e.g., $p K_{m e}, p K_{-}$)
All of the following modeling has been carried out as a function of pore fluid concentration assuming that the pore fluid is aqueous $\mathrm{NaCl}$ and that all changes in $\mathrm{pH}$ can be accommodated by the addition of small amounts of $\mathrm{HCl}$ or $\mathrm{NaOH}$. Computations were carried out in Microsoft Excel from $10^{-5}$ to $10 \mathrm{~mol} / \mathrm{L}$, with five points per decade, and in the range $4.5 \leq \mathrm{pH} \leq 9$, where we note that for a silica surface the point of zero charge is about $\mathrm{pH} 3\left(\mathrm{pH}_{p z c} \approx 3\right)$, which is the $\mathrm{pH}$ at which the EDL collapses. The methods for calculating the Stern-plane potential and hence zeta potential used in this modeling become only approximately valid at $\mathrm{pH} \leq 5$ (Revil et al., 1999a). Modeling has also been carried out as a function of temperature in the range $0^{\circ} \mathrm{C} \leq T \leq 100^{\circ} \mathrm{C}$. Extension beyond this range is only a matter of finding empirical relationships for the density, electrical conductivity, dynamic viscosity, dielectric permittivity and disassociation constant of the bulk fluid which are valid at the higher temperatures and also include pressure. There have been few studies on the effect of temperature upon those parameters entering the HS equation, the most important being those of Reppert and Morgan (2003a, 2003b).

\section{Pore fluid conductivity}

We have used the corrected Sen and Goode (1992a, 1992b) empirical equation to provide the electrical conductivity of the bulk solution (in $\mathrm{S} / \mathrm{m}$ ):

$$
\sigma_{f}\left(T, C_{f}\right)=\left(d_{1}+d_{2} T+d_{3} T^{2}\right) C_{f}-\left(\frac{d_{4}+d_{5} T}{1+d_{6} \sqrt{C_{f}}}\right) C_{f}^{3 / 2},
$$

where $d_{1}=5.6(\mathrm{~S} . \mathrm{L} / \mathrm{m} . \mathrm{mol}), d_{2}=0.27(\mathrm{~S} . \mathrm{L} / \mathrm{m} . \mathrm{mol}) /{ }^{\circ} \mathrm{C}, d_{3}=$ $-1.51 \times 10^{-4}(\mathrm{~S} . \mathrm{L} / \mathrm{m} . \mathrm{mol}) /{ }^{\circ} \mathrm{C}^{2}, \quad d_{4}=2.36\left(\mathrm{~S} / \mathrm{m} /(\mathrm{mol} / \mathrm{L})^{3 / 2}\right)$, $d_{5}=0.099\left(\mathrm{~S} / \mathrm{m} /(\mathrm{mol} / \mathrm{L})^{3 / 2} /{ }^{\circ} \mathrm{C}\right), d_{6}=0.214\left((\mathrm{~mol} / \mathrm{L})^{-1 / 2}\right), T$ is in ${ }^{\circ} \mathrm{C}$ and $C_{f}$ is the salinity of the bulk pore fluid (mol/L).

\section{Pore fluid relative electric permittivity}

Most researchers take a value of $\varepsilon_{f}=\varepsilon_{r} \varepsilon_{o}=80 \times 8.854 \times$ $10^{-12} \mathrm{~F} / \mathrm{m}$ (e.g., Revil et al., 1999a, 1999b), which would correspond approximately to the bulk fluid being an aqueous solution at $25^{\circ} \mathrm{C}$. However, we wish to model the streaming-potential coefficient as a function of pore fluid salinity and temperature, both of which affect the value of the relative dielectric permittivity.

Consequently, we have determined the relative permittivity $\varepsilon_{r}$ (no units) using Gary Olhoeft's empirical equation (Olhoeft, unpublished note, 1980) (Revil et al., 1999b):

$$
\begin{aligned}
\varepsilon_{r}\left(T, C_{f}\right)= & a_{0}+a_{1} T+a_{2} T^{2}+a_{3} T^{3}+c_{1} C_{f} \\
& +c_{2} C_{f}^{2}+c_{3} C_{f}^{3},
\end{aligned}
$$

where $\quad a_{o}=295.68, \quad a_{1}=-1.2283 \mathrm{~K}^{-1}, \quad a_{2}=-2.094 \times$ $10^{-3} \mathrm{~K}^{-2}, a_{3}=-1.41 \times 10^{-6} \mathrm{~K}^{-3}, c_{1}=-13.00 \mathrm{~L} \mathrm{~mol}^{-1}, c_{2}=$ $-1.065\left(\mathrm{~L} \mathrm{~mol}^{-1}\right)^{2}, c_{3}=-0.03006\left(\mathrm{~L} \mathrm{~mol}^{-1}\right)^{3}, T$ is in kelvin and the equation is valid in the range from $273 \mathrm{~K}$ to $373 \mathrm{~K}$ and $C_{f}$ is the salinity of the bulk pore fluid in mol/L. The permittivity in vacuo $\varepsilon=8.854 \times 10^{-12} \mathrm{~F} / \mathrm{m}$ (Lide, 2009).

It is debatable whether the value of $\varepsilon_{r}$ for the bulk fluid is the most appropriate in this modeling. This is because the value of $\varepsilon_{r}$ diminishes within the diffuse layer as one approaches the mineral 
surface (within a few angstroms), taking values as low as five near the Stern plane (Grahame, 1950). It would, perhaps, be more correct to use a smaller value of $\varepsilon_{r}$ that would take into account the reduction of the permittivity in the diffuse layer, which would give larger values of calculated zeta potential at high salinity, and which seem to be supported by recent experimental determinations (Jaafar et al., 2009). Jaafar et al., found that above $0.4 \mathrm{~mol} / \mathrm{L}$ (i.e., for Debye lengths less than $4.65 \times 10^{-10} \mathrm{~m}$ ) the zeta potential becomes constant and may even increase slightly; however, they attributed the behavior to surface charge density saturation not to dielectric saturation.

Unfortunately, at present there exists no theoretical model capable of providing us with a more appropriate effective permittivity value because such a value would depend on the microstructure of the rock. We have carried out some rudimentary CRIM (complex refractive index model) based mixing calculations using the method of Iglesias and Peon Fernandez (2001) with a simplified rock microstructure, and the results support the supposition that the dielectric saturation effect is negligible if the entire pore space contributes to the permittivity used by the modified H-S equation. Additionally, both Booth (1951) and Hunter (1966) provide a model of relative permittivity as a function of local field strength that indicates that the dielectric saturation effect is negligible for most bulk electrolyte solutions (Pride and Morgan, 1991), but again, it is assumed that the whole of the pore fluid contributes to the permittivity to be used in the $\mathrm{H}-\mathrm{S}$ equation.

We may consider that the appropriate permittivity to be used in the H-S equation is that at the shear plane. In which case it would be some exponential mixture of that at the Stern plane, which presumably approaches five after Grahame (1950), and that at the Bjerrum length from the surface, where the fluid ions are more affected by thermal agitation than the presence of the Stern layer, and where the permittivity approaches that given by equation 5 . Under this hypothesis, permittivities of the order of 20 or less would be perfectly possible.

Finally, we note that if we replace the relative electric permittivity calculated by equation 5 in the model by the value of five for all salinities, the result is that the streaming-potential coefficient is increased (becomes less negative) by an order of magnitude and zeta potential is decreased (becoming more negative) by approximately $15 \mathrm{mV}$, which is of the same order of magnitude as the experimental observations of zeta potential at high salinity made by Jaafar et al. (2009). This will be discussed at greater length in Section 5.1.

In this work we have chosen to use the values of fluid permittivity for the bulk fluid (i.e., equation 5) because we considered the solution of the permittivity problem too large to include in this paper. However, we note that often the results of the model give positive zeta potentials at high salinity and low $\mathrm{pH}$ that are not reproduced in experimental results. In these cases we have added a constant zetapotential contribution $\zeta_{o}$ to that calculated by the model for all salinities. This ad hoc parameter improves the behavior of the model at high-salinity data, and is fully described in Section 5. We expect that this parameter will not be required once the model contains a method for including the appropriate electric permittivity.

\section{Pore fluid viscosity}

The dynamic viscosity $\eta_{f}$ of the pore fluid (in Pa.s) was calculated using the Phillips et al. (1978) empirical equation:

$$
\begin{aligned}
\eta_{f}\left(T, C_{f}\right)= & e_{1}+e_{2} \exp \left(\alpha_{1} T\right)+e_{3} \exp \left(\alpha_{2} C_{f}^{m}\right) \\
& +e_{4} \exp \left(\alpha_{3} T+\alpha_{4} C_{f}^{m}\right),
\end{aligned}
$$

where $e_{1}=4.95166 \times 10^{-5}$ Pa.s, $e_{2}=6.034658 \times 10^{-4}$ Pa.s, $e_{3}=9.703832 \times 10^{-5}$ Pa.s, $\quad e_{4}=1.025107 \times 10^{-3}$ Pa.s, $\quad \alpha_{1}=$ $-0.06653081 /{ }^{\circ} \mathrm{C}, \alpha_{2}=-0.1447269 / \mathrm{molal}, \alpha_{3}=-0.02062455 /$ ${ }^{\circ} \mathrm{C}, \alpha_{4}=-0.1301095 / \mathrm{molal}, T$ is in ${ }^{\circ} \mathrm{C}$ and $C_{f}^{m}$ is the molality of the bulk pore fluid. For weak solutions it is possible to say that $C_{f}^{m}=C_{f}$, and consequently, to use salinity in mol/L in place of molality in equation 6 . For stronger solutions it is necessary to calculate the density of the pore fluid and convert $C_{f}$ into $C_{f}^{m}$ using $C_{f}^{m}=C_{f} /\left(\rho_{f}-\left(A C_{f} / 1000\right)\right)$, where $\rho_{f}$ is the pore fluid density in $\mathrm{g} / \mathrm{cm}^{3}$ and $A$ is the atomic mass of the salt in $\mathrm{g} / \mathrm{mol}$ (here for $\mathrm{NaCl}$, $A=58.44 \mathrm{~g} / \mathrm{mol}$ ). Although the difference is small even at high salinity, we have implemented the conversion in our model for all salinities.

Visco-electric effects have been assumed to be negligible in accordance with the results of Lyklema and Overbeek (1961), Hunter (1966), and the interpretation of Pride and Morgan (1991). The Bjerrum length $\lambda_{b}$ is the separation at which the electrostatic interaction between two elementary charges is comparable in magnitude to the thermal energy scale. It is given by $\lambda_{b}=e^{2} / 4 \pi \varepsilon_{r} \varepsilon_{o} k_{b} T$. For an aqueous solution of $\mathrm{NaCl}$ we find that the Bjerrum length remains constant at $\lambda_{b}=7.16 \times 10^{-10} \mathrm{~m}$ for salinities less than about $0.4 \mathrm{~mol} / \mathrm{L}$. It increases substantially until it reaches a value of $13.5 \times 10^{-10} \mathrm{~m}$ at $3.98 \mathrm{~mol} / \mathrm{L}$. At length scales larger than $\lambda_{b}$, fluid ions are more affected by thermal agitation than the presence of the Stern layer. Indeed the local field strength is sufficient to alter the viscosity of the fluid considerably. Figure 3 shows (1) the Bjerrum length $\lambda_{b}$, (2) the Debye screening length $\chi_{d}$, (3) the thickness of the EDL, which we take as twice the Debye screening length $2 \chi_{D}$, and (4) the shear plane distance $\chi_{\zeta}=2.4 \times 10^{-10} \mathrm{~m}$, which has been taken from Revil and Glover (1997) as a function of salinity. It should be noted that the Bjerrum length is greater than the EDL thickness for all salinities greater than about $0.5 \mathrm{~mol} / \mathrm{L}$. In other

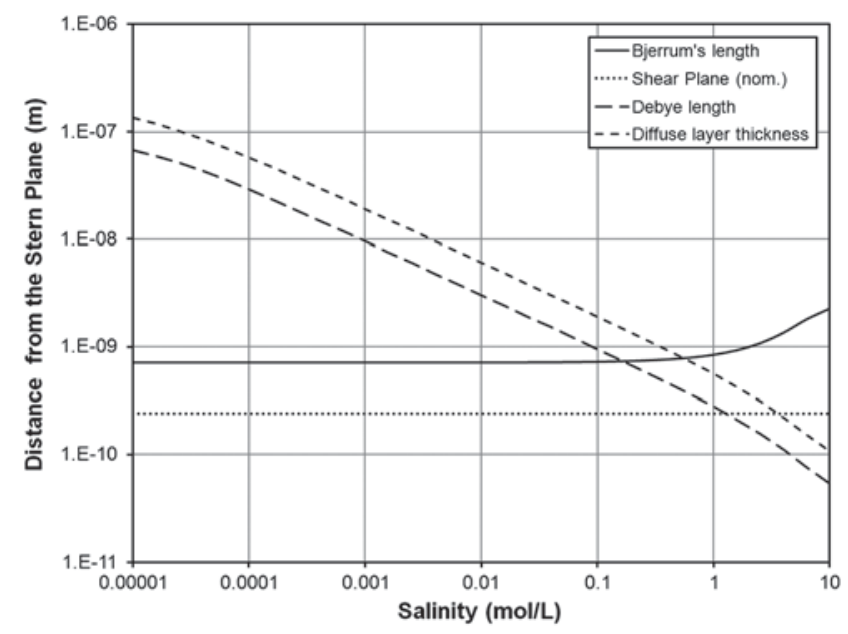

Figure 3. Distance of the shear plane $\left(\chi_{\zeta}\right)$ from the Stern plane as a dotted line (Revil and Glover, 1997) compared with the Bjerrum length $\left(\lambda_{b}\right)$ as a solid line, the Debye screening length $\left(\chi_{d}\right)$ as a long dashed line, and the thickness of the diffuse layer (nominally defined as twice the Debye screening length $\left(2 \chi_{d}\right)$ as a short dashed line, each as a function of pore fluid salinity; $T=25^{\circ} \mathrm{C}$. 
words, interionic electrostatic interactions are significant for the entire EDL, including all of its mobile fraction $\left(\chi>\chi_{\zeta}=\right.$ $2.4 \times 10^{-10} \mathrm{~m}$ ) for salinities greater than $0.5 \mathrm{~mol} / \mathrm{L}$, and it is these electrostatic interactions that increase the fluid viscosity in the double layer. However, the viscosity that occurs in the various versions of the Helmholtz-Smoluchowski equation is the bulk fluid viscosity rather than the local viscosity in the EDL. The bulk viscosity is perturbed negligibly by the local viscosity changes in such a thin layer near the mineral surface, which justifies our approach and that of previous authors (e.g., Pride and Morgan, 1991).

Figure 3 also indicates that $2 \chi_{d}<\chi_{\zeta}$ for salinities greater than about $4 \mathrm{~mol} / \mathrm{L}$. If the EDL had a well-defined thickness equal to $2 \chi_{d}$, it would imply that the streaming-potential coefficient would drop to zero for approximately $C_{f} \geq 4 \mathrm{~mol} / \mathrm{L}$. However, the EDL dies away gradually, which explains why Vinogradov et al. (2010) and Jaafar et al. (2009) were able to make measurements of the streaming-potential coefficient at salinities as high as $5.74 \mathrm{~mol} / \mathrm{L}$.

\section{Physical chemistry of the EDL}

The value of the Stern-plane potential, and hence, the zeta potential depends upon the surface chemistry, which varies from mineral to mineral. We restrict ourselves to a quartz surface in this paper. The discussion of the reactions at a quartz surface in the presence of aqueous fluids has already been well described by many authors (e.g., Iler, 1979; Revil and Glover, 1997, 1998; Revil et al., 1999a) and need not be reproduced in detail here. It is sufficient to say that there are two types of neutral surface group for silica, doubly coordinated siloxal $>\mathrm{Si}^{2} \mathrm{O}^{\circ}$, which can be considered inert, and singly coordinated silanol $>\mathrm{SiOH}^{\circ}$, which reacts readily to give $>\mathrm{SiOH}_{2}^{+}$when $\mathrm{pH}<\mathrm{pH}_{p z c}$, and $>\mathrm{SiO}^{-}$when $\mathrm{pH}>\mathrm{pH}_{p z c}$ (the symbol $>$ in the chemical formulas represents the silica crystal framework). The symbol $\mathrm{pH}_{p z c}$ represents the point of zero charge for the mineral, and is the $\mathrm{pH}$ at which $\left[>\mathrm{SiOH}_{2}^{+}\right]=\left[>\mathrm{SiO}^{-}\right]$, where square brackets indicate concentration. For silica $\mathrm{pH}_{p z c} \approx 3$ (Lorne et al., 1999).

Following the approach of Revil et al. (1999a) we use a 1:1 electrolyte with single valency anions and cations in the $\mathrm{pH}$ range 6-8, where the surface reactions can be written

$$
>\mathrm{SiOH}^{\mathrm{K}} \stackrel{K_{(-)}}{\Leftrightarrow}>\mathrm{SiO}^{-}+\mathrm{H}^{+}
$$

and

$$
>\mathrm{SiOH}^{\mathrm{o}}+\mathrm{Me}^{+} \stackrel{K_{M e}}{\Leftrightarrow}>\mathrm{SiOMe}^{\mathrm{o}}+\mathrm{H}^{+},
$$

where the metal cation is $\mathrm{Me}^{+}$, and for most of our modeling it represents $\mathrm{Na}^{+}$, though it might equally well represent $\mathrm{K}^{+}$or some other single valence cation. Note that the positive surface site $>\mathrm{SiOH}_{2}^{+}$does not occur in equations 7 and 8 because at $\mathrm{pH}>6$ we have assumed that $\left[>\mathrm{SiOH}_{2}^{+}\right]=0$. Hence, there results three types of sites, two neutral ones $\left(>\mathrm{SiOH}^{\circ}\right.$ and $\left.>\mathrm{SiOMe}^{\mathrm{o}}\right)$ and one negative $\left(>\mathrm{SiO}^{-}\right)$.

The position of the equilibrium in equation 7 is given by the disassociation constant for dehydrogenization of silanol surface sites $K_{(-)}$. If $K_{(-)}$is large, equation 7 has an equilibrium toward the right, giving very many more $>\mathrm{SiO}^{-}$sites than $>\mathrm{SiOH}^{\circ}$ sites, and vice versa. The position of the equilibrium in equation 8 is given by the binding constant for cation (sodium) adsorption on quartz $K_{M e}$. If $K_{M e}$ is large, equation 8 has an equilibrium toward the right, where there are very many more $>\mathrm{SiOMe}^{\mathrm{o}}$ sites than $>\mathrm{SiOH}^{\circ}$ sites, and vice versa. So $K_{(-)}$and $K_{M e}$ describe the relative concentrations of the three surface sites. They are unitless. The final parameter of interest is the total surface site density $\Gamma_{\mathrm{s}}^{\mathrm{o}}\left(\right.$ in $\left.\mathrm{m}^{-2}\right)$, which is the sum of the surface site densities for each of the three types of surface site.

\section{Fluid pH}

The fluid $\mathrm{pH}$ is required to calculate the Stern-plane potential and surface conductance. For an aqueous electrolyte in contact with the atmosphere the $\mathrm{pH}$ is defined by (1) the disassociation constant of water $K_{w}$, which varies with temperature, (2) the reaction of water with carbon dioxide from the atmosphere in a two step process, (3) the addition of acid, and/or (4) the addition of a base.

The value of $K_{w}$ varies with temperature. We have obtained an equation by fitting a polynomial to $K_{w}$ data obtained from Lide (2009), which is approximately valid in the range $0^{\circ} \mathrm{C} \leq T \leq 100^{\circ} \mathrm{C}$ :

$$
\begin{aligned}
K_{w}= & 6.9978 \times 10^{-16}+5.0178 \times 10^{-16} T \\
& -2.4434 \times 10^{-17} T^{2}+7.1948 \times 10^{-19} T^{3} .
\end{aligned}
$$

It is worthwhile noting that this variation implies that the $\mathrm{pH}$ of pure water is 7.47 at $0^{\circ} \mathrm{C}$, about 7 at $25^{\circ} \mathrm{C}$ and 6.14 at $100^{\circ} \mathrm{C}$.

The reaction of water with atmospheric carbon dioxide occurs in two steps:

$$
\mathrm{H}_{2} \mathrm{O}+\mathrm{CO}_{2} \stackrel{K_{1}}{\Leftrightarrow} \mathrm{HCO}_{3}^{-}+\mathrm{H}^{+},
$$

and

$$
\mathrm{HCO}_{3}^{-} \stackrel{K_{2}}{\Leftrightarrow} \mathrm{CO}_{3}^{2-}+\mathrm{H}^{+} .
$$

We have used equilibrium constants $K_{l}=10^{-7.53}$ and $K_{2}=10^{-10.3}$ after Wu et al. (1991) and Revil et al. (1999a). These two constants may depend upon temperature. We have assumed them to be independent of temperature, in the range $15^{\circ} \mathrm{C}$ to $25^{\circ} \mathrm{C}$.

The result of equation 9 and processes 10 and 11 is that pure water in equilibrium with atmospheric carbon dioxide tends to be acidic. However, this initial acidity is reduced substantially when the fluid is equilibrated with the silica of the rock matrix. The process fluid can, of course, take any value of $\mathrm{pH}$ depending on the addition of an acid or a base (or both).

In this paper, we have assumed that the pore fluid is aqueous $\mathrm{NaCl}$ (though the equations would work equally well for other $1: 1$ electrolytes providing the values of the relevant parameters were changed accordingly). The salinity of the solution is $C_{f}$ (in mol/L). We assume that a more acidic $\mathrm{pH}$ is obtained by adding $\mathrm{HCl}$ to the fluid in a concentration equal to $C_{a}$ (in mol/L), and a more basic $\mathrm{pH}$ is obtained by adding $\mathrm{NaOH}$ to the fluid in a concentration equal to $C_{b}$ (in mol/L). Each addition of acid or base will perturb the concentration of $\mathrm{Cl}^{-}$ions and $\mathrm{Na}^{+}$ions in the solution, respectively. Acid and base can be added together and their effect on $\mathrm{pH}$ will balance out; however, an augmentation of the concentration of $\mathrm{Cl}^{-}$ions and $\mathrm{Na}^{+}$ions in the solution will still occur and this is taken account of in the model by the terms $10^{-\mathrm{pH}}$ for hydrogen ions, $10^{(\mathrm{pH}-\mathrm{pKw})}$ for hydroxyl ions, $C_{a}$ for chloride ions that are added as 
$\mathrm{HCl}$, and $C_{b}$ for sodium ions that are added as $\mathrm{NaOH}$. Hence, we need to account for the addition of acid and base to the pore fluid solution to ensure that the ionic fluid concentrations in the model reflect those in a real pore fluid at a given $\mathrm{pH}$.

ThepH of the silica- $\mathrm{H}_{2} \mathrm{O}-\mathrm{CO}_{2}$ system is defined by the cubic equation (Revil et al., 1999a)

$$
C_{H^{+}}^{3}-\Delta C C_{H^{+}}^{2}-\left(K_{w}+K_{1}\right) C_{H^{+}}-2 K_{1} K_{2}=0,
$$

where $\Delta C=C_{a}-C_{b}$ and $\mathrm{pH}=-\log _{10}\left(\mathrm{C}_{\mathrm{H}}^{+}\right)$.

There are two ways that we can build the link between acid and base concentrations and $\mathrm{pH}$ into our model. The first is to define the $\mathrm{pH}$ and then calculate the respective concentrations of acid and base required, which will then give us the augmentation in $\mathrm{Cl}^{-}$and $\mathrm{Na}^{+}$ ions in the pore fluid. If this approach is taken, we must assume that either $C_{a}$ or $C_{b}$ is zero to ensure that the solution of equation 12 is unique. The second approach is to solve equation 12 for given values of $C_{a}$ and $C_{b}$, and use the $\mathrm{pH}$ thus calculated in the model. We have implemented both approaches. The first is more convenient for fitting the model to experimental data where the $\mathrm{pH}$ of the pore fluid is known and has been used for the results presented in this paper, whereas the second is more convenient if the composition for the pore fluid is defined, for example, in experiment planning. An analytical solution of equation 12 is given in Appendix A.

\section{Debye screening length and shear-plane distance}

The Debye screening length is given by

$$
\chi_{d}=\sqrt{\frac{\varepsilon_{o} \varepsilon_{r} k_{b} T}{2000 \mathrm{~N} e^{2} I_{f}}},
$$

\begin{tabular}{|c|c|c|c|}
\hline$k_{b}=1.38 \times 10^{-23}$ & Boltzmann's & $\left(\mathrm{J} \mathrm{K}^{-1}\right)$ & Lide (2009) \\
\hline$e=1.602 \times 10^{-19}$ & $\begin{array}{l}\text { constant } \\
\text { elementary } \\
\text { charge }\end{array}$ & (C) & Lide (2009) \\
\hline $\mathrm{N}=6.022 \times 10^{23}$ & Avogadro's & $\left(\mathrm{mol}^{-1}\right)$ & Lide (2009) \\
\hline$\varepsilon_{\mathrm{o}}=8.854 \times 10^{-12}$ & $\begin{array}{l}\text { constant } \\
\text { electrical } \\
\text { permittivity }\end{array}$ & $\left(\mathrm{F} \mathrm{m}^{-1}\right)$ & Lide (2009) \\
\hline$\varepsilon_{\mathrm{r}}$ & $\begin{array}{l}\text { in vacuo } \\
\text { relative } \\
\text { electrical } \\
\text { permittivity }\end{array}$ & $(-)$ & $\begin{array}{c}\text { From } \\
\text { equation } 5\end{array}$ \\
\hline$I_{f}$ & ionic strength & $(\mathrm{mol} / \mathrm{L})$ & $\begin{array}{c}\text { From } \\
\text { equation } 14\end{array}$ \\
\hline$T$ & temperature & $(\mathrm{K})$ & Model variab \\
\hline
\end{tabular}

where

The factor of 2000 arises due to the units for ionic strength being here mol/L. This equation is often found cited with a 2 in place of the 2000 , in which case the units for $I_{f}$ would be $\mathrm{mol} \mathrm{m}^{-3}$.

The ionic strength is given by

$$
I_{f}=\frac{1}{2} \sum_{i}^{n} Z_{i}^{2} C_{i}^{f} .
$$

In this work the acid and alkali contributions are usually small compared with that of the dissolved $\mathrm{NaCl}$. Hence, for the most common scenarios where $C_{f}>10^{-5} \mathrm{~mol} / \mathrm{L}$ and $5<\mathrm{pH}<9$, we can say that $I_{f} \approx C_{f}$.

There currently does not exist a method for independently evaluating the shear-plane distance. However, we have used the value obtained by Revil and Glover (1997) when they fitted their model to the data of Scales et al. (1990), which is $\chi_{\zeta}=2.4 \times 10^{-10} \mathrm{~m}$.

The value of the Debye screening length generated in this work varied from $1.75 \times 10^{-11} \mathrm{~m}$ to $9.68 \times 10^{-8} \mathrm{~m}$ for $C_{f}=3.98 \mathrm{~mol} / \mathrm{L}$ and $T=100^{\circ} \mathrm{C}$, and $C_{f}=10^{-5} \mathrm{~mol} / \mathrm{L}$ and $T=0^{\circ} \mathrm{C}$, respectively, both at $\mathrm{pH}=7$. The thickness of the diffuse layer may be considered to be approximately twice the Debye length. For $C_{f}=0.4 \mathrm{~mol} / \mathrm{L}$ at $\mathrm{pH}=7$ and $T=25^{\circ} \mathrm{C}$ equation 13 gives $2 \chi_{d}=9.31 \times 10^{-10}$. Because $2 \chi_{d} \geq \chi_{\zeta}$, we can see that a significant amount of the double layer (74.2\%) is moved during electrokinetic coupling, and this amount increases swiftly to approach $100 \%$ of the double layer for lower pore fluid concentrations. The condition that $2 \chi_{d}=\chi_{\zeta}$ is reached at a concentration of $3.395 \mathrm{~mol} / \mathrm{L}$, but streaming potentials are possible at higher salinity because the EDL decays away exponentially so that the arbitrary limit on its size given by $2 \chi_{d}$ is not a true reflection on the extent of the EDL. The EDL extends beyond $2 \chi_{d}$, but very weakly, and it is this weak portion of the EDL that gives rise to the small streamingpotential coefficients at concentrations greater that $3.395 \mathrm{~mol} / \mathrm{L}$.

\section{Stern-plane potential}

The Stern-plane potential was calculated using the techniques described in Revil and Glover (1997) and in Revil et al. (1999a), and is given by

$$
\begin{gathered}
\varphi_{d}=\frac{2 k_{b} T}{3 e} \ln \left(\frac{\sqrt{8 \times 10^{3} \varepsilon_{r} \varepsilon_{o} k_{b} T \mathrm{~N}}\left(10^{-\mathrm{pH}}+K_{M e} C_{f}\right)}{2 e \Gamma_{s}^{o} K_{(-)}}\right. \\
\left.\left[\frac{C_{a}+C_{b}+C_{f}+10^{-\mathrm{pH}}+10^{\mathrm{pH}-p K w}}{\sqrt{I_{f}}}\right]\right)
\end{gathered}
$$

\begin{tabular}{|c|c|c|c|}
\hline$k_{b}=1.38 \times 10^{-23}$ & & $\left(\mathrm{~J} \mathrm{~K}^{-1}\right)$ & Lide (2009) \\
\hline$e=1.602 \times 10^{-19}$ & elementary charge & (C) & Lide (2009) \\
\hline $\mathrm{N}=6.022 \times 10^{23}$ & Avogadro's & $\left(\mathrm{mol}^{-1}\right)$ & Lide (2009) \\
\hline$\varepsilon_{\mathrm{o}}=8.854 \times 10^{-12}$ & $\begin{array}{l}\text { electrical } \\
\text { permittivity } \\
\text { in vacuo }\end{array}$ & $\left(\mathrm{Fm}^{-1}\right)$ & Lide (2009) \\
\hline$Z_{i}=1$ & $\begin{array}{l}\text { valence of the } \\
\text { ionic species } i\end{array}$ & $(-)$ & Lide (2009) \\
\hline$\varepsilon_{r}$ & $\begin{array}{l}\text { relative electrical } \\
\text { permittivity }\end{array}$ & $(-)$ & $\begin{array}{c}\text { From } \\
\text { equation } 5\end{array}$ \\
\hline$I_{f}$ & ionic strength & $(\mathrm{mol} / \mathrm{L})$ & $\begin{array}{c}\text { From } \\
\text { equation } 14\end{array}$ \\
\hline$K_{M e}$ & $\begin{array}{l}\text { binding constant } \\
\text { for cation } \\
\text { (usually sodium) } \\
\text { adsorption } \\
\text { on quartz }\end{array}$ & $(-)$ & $\begin{array}{c}\text { Model } \\
\text { variable }\end{array}$ \\
\hline
\end{tabular}

where:

(continued) 


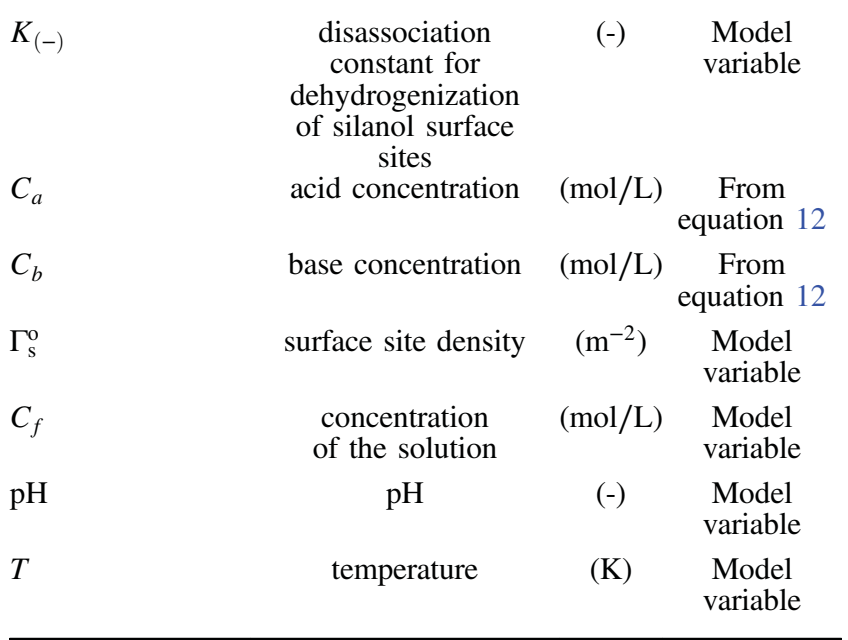

While the fundamental constants are known to great accuracy, there is some considerable uncertainty over the exact value of other parameters such as $K_{M e}, K_{(-)}$, and $\Gamma_{\mathrm{s}}^{\mathrm{o}}$ as discussed earlier, in Revil et al. (1999a), and in detail in the Model Parameters section below.

The theoretical values of Stern-plane potential arrived at in this work were between $-181.6 \mathrm{mV}$ and $15.1 \mathrm{mV}$ for $C_{f}=$ $10^{-5} \mathrm{~mol} / \mathrm{L}$ and $T=100^{\circ} \mathrm{C}$, and $C_{f}=3.98 \mathrm{~mol} / \mathrm{L}$ and $T=$ $0^{\circ} \mathrm{C}$, respectively, and both with $\mathrm{pH}=7, \quad p K_{M e}=7.5$, $p K_{(-)}=7$, and $\Gamma_{s}^{o}=10$ sites $\mathrm{nm}^{-3}$.

\section{Zeta potential}

The electrical potential $\varphi$ in the EDL has, approximately, an exponential distribution given by $\varphi \approx \varphi_{d} \exp \left(-\chi / \chi_{d}\right)$, where $\varphi_{d}$ is the Stern-plane potential $(\mathrm{V}), \chi_{d}$ is the Debye screening length $(\mathrm{m})$ and $\chi$ is the distance from the mineral surface. It is, in fact, the solution of the linearized approximation of the Poisson-Boltzmann equation for the EDL (equation 35 of Revil and Glover, 1997). The exponential form of equation 16 is often called the Debye-Hückel approximation.

The zeta potential can then be calculated using (Revil and Glover, 1997; 1998; Revil et al., 1999a)

$$
\zeta \approx \varphi_{d} \exp \left(-\chi_{\zeta} / \chi_{d}\right)
$$

where

\begin{tabular}{cccc}
$\varphi_{d}$ & $\begin{array}{c}\text { Stern plane } \\
\text { potential } \\
\text { Debye screening } \\
\text { length } \\
\chi_{d}\end{array}$ & (V) & From equation 15 \\
$\chi_{\zeta}=2.4 \times 10^{-10}$ & $\begin{array}{c}\text { From equation 13 } \\
\text { distance }\end{array}$ & (m) & $\begin{array}{c}\text { Revil and Glover } \\
(1997)\end{array}$ \\
\hline
\end{tabular}

The theoretical values of the zeta potential arrived at in this work were between $-201 \mathrm{mV}$ and zero for $C_{f}=10^{-5} \mathrm{~mol} / \mathrm{L}$ and $T=$ $100^{\circ} \mathrm{C}$, and $C_{f}=3.98 \mathrm{~mol} / \mathrm{L}$ and $T=0^{\circ} \mathrm{C}$, respectively, and both with $\mathrm{pH}=7, p K_{M e}=7.5, p K_{(-)}=7$, and $\Gamma_{\mathrm{s}}^{\mathrm{o}}=10$ sites $\mathrm{nm}^{-3}$.

\section{Surface conduction}

The surface conductance was also calculated using the techniques described in Revil and Glover $(1997,1998)$ and in Revil et al. (1999a). The surface conductance is given by

$$
\Sigma_{s}=\Sigma_{s}^{\mathrm{EDL}}+\Sigma_{s}^{\text {Prot }}+\Sigma_{s}^{\text {Stern }},
$$

where

$$
\begin{aligned}
& \Sigma_{s}^{\text {Stern }}=
\end{aligned}
$$

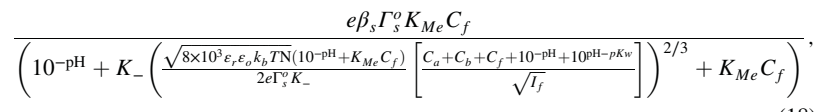

and where

$$
\begin{aligned}
\Sigma_{s}^{\mathrm{EDL}}= & R\left(\left[\left(B_{N a^{+}} C_{f}+B_{H^{+}} 10^{-\mathrm{pH}}\right)\left(\left(S\left(\frac{10^{-\mathrm{pH}}+C_{f} K_{M e}}{2 e \Gamma_{s}^{o} K_{-}}\right)\right)^{-1 / 3}-1\right)\right]+\right. \\
& {\left.\left[\left(B_{C l^{-}} C_{f}+B_{O H^{-}} 10^{\mathrm{pH}-p K_{w}}\right)\left(\left(S\left(\frac{10^{-\mathrm{pH}}+C_{f} K_{M e}}{2 e \Gamma_{s}^{o} K_{-}}\right)\right)^{+1 / 3}-1\right)\right]\right), }
\end{aligned}
$$

and where

$$
\begin{aligned}
& R=\sqrt{\frac{2 \times 10^{-3} \varepsilon_{r} \varepsilon_{o} k_{b} T \mathrm{~N}}{C_{f}+10^{-\mathrm{pH}}}} \text { and } \\
& S=\sqrt{8 \times 10^{3} \varepsilon_{r} \varepsilon_{o} k_{b} T \mathrm{~N}\left(C_{a}+C_{b}+C_{f}+10^{-\mathrm{pH}}+10^{\mathrm{pH}-p K_{w}}\right)} .
\end{aligned}
$$

In equations 19 and $20 \mathrm{pH}=-\log _{10}\left(C_{H}^{+}\right), p K_{w}=-\log _{10}\left(K_{w}\right)$ and $K_{w}$ is the disassociation constant of water that is given by equation 9. The terms $B_{i}$ are the equivalent ionic mobilities for each ion, where $B_{i}=\beta_{i}+2 \varepsilon_{r} \varepsilon_{o} k_{b} T / \eta_{f} e Z_{i}$ and where $\beta_{i}$ is the ionic mobility of each ion:

\begin{tabular}{llll}
$\beta_{\mathrm{Na}+}=5.20 \times 10^{-8}$ & $\begin{array}{c}\text { Ionic mobility } \\
\text { of sodium ions }\end{array}$ & $\left(\mathrm{m}^{2} \mathrm{~s}^{-1} \mathrm{~V}^{-1}\right)$ & $\begin{array}{c}\text { Crow } \\
(1988)\end{array}$ \\
$\beta_{\mathrm{H}+}=3.63 \times 10^{-7}$ & $\begin{array}{c}\text { Ionic mobility of } \\
\text { hydrogen ions }\end{array}$ & $\left(\mathrm{m}^{2} \mathrm{~s}^{-1} \mathrm{~V}^{-1}\right)$ & $\begin{array}{c}\text { Crow } \\
(1988)\end{array}$ \\
$\beta_{\mathrm{Cl}-}=7.90 \times 10^{-8}$ & $\begin{array}{c}\text { Ionic mobility of } \\
\text { chloride ions }\end{array}$ & $\left.\mathrm{m}^{2} \mathrm{~s}^{-1} \mathrm{~V}^{-1}\right)$ & $\begin{array}{c}\text { Crow } \\
(1988)\end{array}$ \\
$\beta_{\mathrm{OH}-}=2.05 \times 10^{-7}$ & $\begin{array}{c}\text { Ionic mobility of } \\
\text { hydroxyl ions }\end{array}$ & $\left(\mathrm{m}^{2} \mathrm{~s}^{-1} \mathrm{~V}^{-1}\right)$ & $\begin{array}{c}\text { Crow } \\
\text { (1988) }\end{array}$ \\
\hline
\end{tabular}

The ionic mobility controls the size of the electro-migration contribution to the diffuse layer conductance, whereas the term $2 \varepsilon_{r} \varepsilon_{o} k_{b} T / \eta_{f} e Z_{i}$ term controls the size of the electro-osmotic contribution to the diffuse layer conductance. The equivalent ionic mobilities $B_{i}$ thus account for both processes.

Although the contribution from the diffuse layer $\Sigma_{s}^{\mathrm{EDL}}$ was shown to be negligible by Revil and Glover (1998) for a small range of parameters, we have implemented it in full in this model to be as complete as possible.

The contribution of the protons (and electrons) is thought to involve conduction along the surface only (O'Konski, 1960) and to be a function of surface site density but not of salinity (Revil and Glover, 1998). Watillon and de Backer (1970) find that the surface conduction for a silica glass capillary full of pure water is $\Sigma_{s}=2.4 \times 10^{-9} \mathrm{~S}$. Given that Revil and Glover (1998) find that $\Gamma_{\mathrm{s}}^{\mathrm{o}}=(1.0 \pm 0.06) \times 10^{19}$ sites $/ \mathrm{m}^{2}$ for the same data, we have assumed linearity and used the following formulation to calculate the proton contribution to the surface conductance: 


$$
\Sigma_{s}^{\text {Prot }}=c_{\text {Prot }} \Gamma_{s}^{\mathrm{o}}=2.4 \times 10^{-28} \Gamma_{s}^{\mathrm{o}} .
$$

where $c_{\text {prot }}=2.4 \times 10^{-28} \mathrm{Sm}^{2} /$ site is the proton surface conductance contribution rate. All the other parameters in equations 16 to 20 have already been described except $\beta_{s}$, which is the ionic surface mobility (in $\mathrm{m}^{2} \mathrm{~s}^{-1} \mathrm{~V}^{-1}$ ). We have used $\beta_{s}=$ $5 \times 10^{-9} \mathrm{~m}^{2} \mathrm{~s}^{-1} \mathrm{~V}^{-1}$ from Revil et al. (1998).

The theoretical values of the surface conductance arrived at in this work were between $8.76 \times 10^{-9} \mathrm{~S}$ and $2.64 \times 10^{-9} \mathrm{~S}$ for $C_{f}=$ $3.98 \mathrm{~mol} / \mathrm{L}$ and $T=100^{\circ} \mathrm{C}$, and $C_{f}=10^{-5} \mathrm{~mol} / \mathrm{L}$ and $T=0^{\circ} \mathrm{C}$, respectively, and both with $\mathrm{pH}=7, p K_{M e}=7.5, p K_{(-)}=7$, and $\Gamma_{\mathrm{s}}^{\mathrm{o}}=10$ sites $\mathrm{nm}^{-3}$.

\section{Streaming-potential coefficient}

The streaming-potential coefficient has been calculated from the values of the pore fluid dielectric permittivity $\varepsilon_{f}=\varepsilon_{r} \varepsilon_{o}$, zeta potential $\zeta$, bulk fluid conductivity $\sigma_{f}$, pore fluid viscosity $\eta_{f}$, and surface conductance $\Sigma_{s}$, all calculated previously, together with the grain diameter $d$, cementation exponent $m$, and formation factor $F=\phi^{-m}$, where $\phi$ is the porosity, using the equation 4 of Glover and Déry (2010)

$$
C_{s}=\frac{\Delta V}{\Delta P}=\frac{d \varepsilon_{f} \zeta}{\eta_{f}\left(d \sigma_{f}+6 \Sigma_{s}(F-1)\right)}
$$

The grain diameter $d$, cementation exponent $m$, formation factor $F$, and porosity $\phi$ describe the microstructure of the rock matrix, and allow the previous modeling to be applied to real geological materials, such as rocks, sands and soils.

\section{MODEL PARAMETERS}

Although there are 18 independently adjustable parameters in the model, many are either model variables or are fixed by independent measurements. We will discuss the values of each of the main adjustable parameters in turn before describing the modeled curves for the streaming-potential coefficient, zeta potential, and surface conduction in the next section.

Temperature, salinity, and $\mathrm{pH}$ are all considered to be model variables. These variables are either fixed, or the model is run as a function of one or more of them.

Grain size, porosity, cementation exponent, and formation factor are all rock-specific microstructural parameters that are fixed by whatever rock sample one wishes to model.

The four effective ionic mobilities in a given aqueous fluid are independently available from electrochemical research (e.g., Crow, 1988). The equilibrium constants $K_{1}=10^{-7.53}$ and $K_{2}=10^{-10.3}$ are likewise known from studies made on the silica- $\mathrm{H}_{2} \mathrm{O}-\mathrm{CO}_{2}$ system (e.g., Wu et al., 1991). There is more uncertainty over the value of the six remaining variables; each is discussed at greater length below.

\section{Surface-site density}

The range of this parameter for silica surfaces varies considerably because silica surfaces can exist in a variety of forms. For simply coordinated surface groups on amorphous silica, published values for the surface-site-density values include 4.6 sites $\mathrm{nm}^{-2}$ (Iler, 1979), five sites $\mathrm{nm}^{-2}$ (Park and Regalbuto, 1995) and six sites $\mathrm{nm}^{-2}$ (Kosmulski, 1996). For crystalline silica, Hiemstra and van Riemsdijk (1990) use 9.6 sites $\mathrm{nm}^{-2}$ for the (001) crystallographic plane and six sites $\mathrm{nm}^{-2}$ for the (010) crystallographic plane. For crushed quartz, Jørgensen and Jensen (1967) obtain a lower value of 2.6 sites $\mathrm{nm}^{-2}$, which can be attributed to the crushing process (Revil et al., 1999a), whereas at high $\mathrm{pH}$ values and during dissolution, values as high as 25 sites $\mathrm{nm}^{-2}$ are theoretically possible and confirmed by acid/base titration measurements at high $\mathrm{pH}$ values (Tadros and Lykelma, 1969; Yates and Healy, 1976). Revil and Glover (1998) find a value of $10.0 \pm 0.6$ sites $\mathrm{nm}^{-2}$ while modeling the data of Watillon and de Backer (1970), which was made using an aqueous $\mathrm{KNO}_{3}$ electrolyte at $\mathrm{pH}=6.8$ in a silica glass capillary. Later, Revil et al. (1999a) refined the surface site density to 9.3 sites $\mathrm{nm}^{-2}$ modeling the same Watillon and de Backer (1970) data, and also state that they consider that the value should generally lie in the range five to 10 sites $\mathrm{nm}^{-2}$ providing $\mathrm{pH} \leq 8$. We have used a value of 10 sites $\mathrm{nm}^{-2}$.

We intend to publish a subsequent paper that analyses the sensitivity of the model to this parameter in detail. Briefly, however, the variation of this parameter from 2.5 and 25 sites $\mathrm{nm}^{-2}$ for a $\mathrm{NaCl}$ pore fluid with a $\mathrm{pH}$ between 5 and 8 , while keeping the other parameters constant $\left(p K_{m e}=7.5, p K_{(-)}=7.1, \chi_{\zeta}=2.4 \times 10^{-10} \mathrm{~m}\right.$, $c_{\text {prot }}=2.4 \times 10^{-28} \mathrm{Sm}^{2} /$ site, $\beta_{s}=5 \times 10^{-9} \mathrm{~m}^{2} \mathrm{~s}^{-1} \mathrm{~V}^{-1}, \quad d=2 \times$ $10^{-5} \mathrm{~m}, m=1.8, \phi=0.2$ ), has the effect of changing the streaming potential negligibly for $C_{f}>0.01 \mathrm{~mol} / \mathrm{L} \mathrm{NaCl}$, and diminishing it by up to one order of magnitude for $C_{f}<0.01 \mathrm{~mol} / \mathrm{L} \mathrm{NaCl}$, although the strength of the low salinity effect is dependent upon the microstructural properties of the rock (grain size, formation factor, porosity, etc.). The change from 2.5 to 25 sites $\mathrm{nm}^{-2}$ also has the effect of reducing the sensitivity of the streaming-potential coefficient to $\mathrm{pH}$ in the range 5 to 8 ; at $\Gamma_{\mathrm{s}}^{\mathrm{o}}=2.5$ sites $\mathrm{nm}^{-2}$, there is approximately half an order of magnitude difference between the streaming-potential curve for $\mathrm{pH} 5$ and those for $\mathrm{pH} 7$ and $\mathrm{pH} 8$ (which are very similar), while for 25 sites $\mathrm{nm}^{-2}$ the difference is about twofold.

\section{Binding constant for cation adsorption}

We have used a value for the binding constant for cation (sodium) adsorption on quartz of $p K_{m e}=7.5$. The actual value is not well known, and varies according to which is the dominant cation. For silica we have $p K_{m e}\left(\mathrm{Li}^{+}\right)=7.8$ and $p K_{m e}\left(\mathrm{Na}^{+}\right)=7.1$ (Dove and Rimstidt, 1994), $\quad p K_{m e}\left(\mathrm{Li}^{+}\right)=7.7, \quad p K_{m e}\left(\mathrm{Na}^{+}\right)=7.5 \quad$ and $p K_{m e}\left(\mathrm{Cs}^{+}\right)=7.2$ (Kosmulski, 1996), and $p K_{m e}\left(\mathrm{Na}^{+}\right)=3.25$ and $p K_{m e}\left(\mathrm{~K}^{+}\right)=2.8$ (Revil et al., 1999a). For muscovite, which shares many of the same surface characteristics as silica, the measured values are $p K_{m e}\left(\mathrm{Li}^{+}\right)=5.5, \quad p K_{m e}\left(\mathrm{Na}^{+}\right)=5.5$, $p K_{m e}\left(\mathrm{~K}^{+}\right)=3.2$ and $p K_{m e}\left(\mathrm{Cs}^{+}\right)=2.8$ (Scales et al., 1990).

We also intend to publish a sensitivity analysis to this parameter in a subsequent paper. However, variation of this parameter between 3.25 and 7.5 for a $\mathrm{NaCl}$ pore fluid with a $\mathrm{pH}$ between 5 and 8 while keeping the other parameters constant $\left(\Gamma_{\mathrm{s}}^{\mathrm{o}}=10\right.$ sites $\mathrm{nm}^{-2}$, $p K_{(-)}=7.1, \chi_{\zeta}=2.4 \times 10^{-10} \mathrm{~m}, \quad c_{\text {prot }}=2.4 \times 10^{-28} \mathrm{Sm}^{2} /$ site, $\left.\beta_{s}=5 \times 10^{-9} \mathrm{~m}^{2} \mathrm{~s}^{-1} \mathrm{~V}^{-1}, \quad d=2 \times 10^{-5} \mathrm{~m}, \quad m=1.8, \quad \phi=0.2\right)$ has little effect for $C_{f}<0.01 \mathrm{M} \mathrm{NaCl}$, but seems to have a drastic effect in the range $0.01>C_{f}>2 \mathrm{~mol} / \mathrm{L} \mathrm{NaCl}$ where positive streaming potentials are predicted as $p K_{m e} \rightarrow 3.25$, which is still within the range of values measured by experimentalists. This is clearly an important sensitivity to understand. 


\section{Disassociation constant for dehydrogenization}

We have used a value for the disassociation constant for dehydrogenization of silanol surface sites of $p K_{(-)}=7.1$. Again, the actual value is not well known. However, experimentally we have $p K_{(-)}=6.8$ (Dove and Rimstidt, 1994), $p K_{(-)}=6.5$ (Kosmulski, 1996), and $p K_{(-)}=7.5$ (Hiemstra and van Riensdijk, 1990), whereas a modeling study predicts that $p K_{(-)}=8.5$ (Rustad, 1998), and Revil et al. (1999a) have used 7.4 - 7.5 in their modeling.

A brief sensitivity of the model to this parameter shows that the variation of this parameter from 6.5 to 8.5 for a $\mathrm{NaCl}$ pore fluid with a $\mathrm{pH}$ between 5 and 8 while keeping the other parameters constant $\left(\Gamma_{\mathrm{s}}^{\mathrm{o}}=10\right.$ sites $\mathrm{nm}^{-2}, p K_{m e}=7.5, \chi_{\zeta}=2.4 \times 10^{-10} \mathrm{~m}$, $c_{\text {prot }}=2.4 \times 10^{-28} \mathrm{Sm}^{2} /$ site, $\beta_{s}=5 \times 10^{-9} \mathrm{~m}^{2} \mathrm{~s}^{-1} \mathrm{~V}^{-1}, \quad d=2 \times$ $10^{-5} \mathrm{~m}, m=1.8, \phi=0.2$ ) decreases the streaming-potential coefficient for all salinities except those where $C_{f}>1 \mathrm{~mol} / \mathrm{L}$. The decrease is small for solutions with $\mathrm{pH} 7$ and $\mathrm{pH} 8$, leading to an approximately twofold decrease, but is larger for $\mathrm{pH} 6$ and amounts to more than an order of magnitude for $\mathrm{pH} 5$.

\section{The shear-plane distance}

There exists few independent measurements of the shear-plane distance $\chi_{\zeta}$. Smith (1976) found $\chi_{\zeta}=5.0 \times 10^{-10} \mathrm{~m}$, whereas Revil and Glover (1997) used $\chi_{\zeta}$ as an adjustable parameter in their model to obtain $\chi_{\zeta}=2.4 \times 10^{-10} \mathrm{~m}$. A similar fitting procedure was used by Ishido and Mizutani (1981) to obtain $\chi_{\zeta}=2.0 \times 10^{-9} \mathrm{~m}$. We have chosen to use $\chi_{\zeta}=2.4 \times 10^{-10} \mathrm{~m}$. It should be noted that Revil et al. (1999a) use $\chi_{\zeta}=0 \mathrm{~m}$, which corresponds to the shear plane and Stern plane being colocated (i.e., fluid flow transports the entire diffuse layer). Although this is a useful tool to reduce the number of parameters in the model by one, we consider it to be unduly restrictive because the modeled streaming-potential coefficient at high salinity is sensitive to changes in this parameter.

A brief sensitivity of the model to this parameter shows that the augmentation of this parameter between $2.4 \times 10^{-11} \mathrm{~m}$ and $2.4 \times 10^{-9} \mathrm{~m}$ for a $\mathrm{NaCl}$ pore fluid with a $\mathrm{pH}$ between 5 and 8 while keeping the other parameters constant $\left(\Gamma_{\mathrm{s}}^{\mathrm{o}}=10\right.$ sites $\mathrm{nm}^{-2}$, $p K_{m e}=7.5, \quad p K_{(-)}=7.1, \quad c_{\text {prot }}=2.4 \times 10^{-28} \mathrm{Sm}^{2} / \mathrm{site}, \quad \beta_{s}=$ $\left.5 \times 10^{-9} \mathrm{~m}^{2} \mathrm{~s}^{-1} \mathrm{~V}^{-1}, d=2 \times 10^{-5} \mathrm{~m}, m=1.8, \phi=0.2\right)$ reduces the streaming-potential coefficient curves for all four $\mathrm{pH}$ values negligibly for $\chi_{\zeta}$ changing from $2.4 \times 10^{-11} \mathrm{~m}$ and $2.4 \times$ $10^{-10} \mathrm{~m}$, but reduces the streaming potential by half an order of magnitude for all four $\mathrm{pH}$ values when augmenting the value further to $2.4 \times 10^{-9} \mathrm{~m}$. Interestingly, this last value $\left(\chi_{\zeta}=2.4 \times 10^{-9} \mathrm{~m}\right)$ provides model curves that are an extremely good fit to the data.

\section{Contributions to surface conduction}

The surface conduction has contributions from so-called proton conduction, from the Stern plane and from the diffuse layer. The contributions from the Stern plane and diffuse layers are not input parameters because they are calculated in the model. We have used a value of $c_{\text {prot }}=2.4 \times 10^{-28} \mathrm{Sm}^{2} /$ site for the proton surface conductance contribution rate based on experimental determinations using pure water on silica glass at $20^{\circ} \mathrm{C}-25^{\circ} \mathrm{C}$ by Watillon and de Backer (1970) and then use equation 21 to give a value of
$\Sigma_{s}^{\text {Prot }}=2.4 \times 10^{-9} \mathrm{~S}$, which coincides with the value used by Revil et al. (1999a).

A brief sensitivity of the model to this parameter shows that the augmentation of this parameter between $2.4 \times 10^{-29} \mathrm{~m}$ and $2.4 \times 10^{-27} \mathrm{~m}$ for an $\mathrm{NaCl}$ pore fluid with a $\mathrm{pH}$ between 6 and 8 while keeping the other parameters constant $\left(\Gamma_{\mathrm{s}}^{\mathrm{o}}=10\right.$ sites $\mathrm{nm}^{-2}, \quad p K_{m e}=7.5, \quad p K_{(-)}=7.1, \quad \chi_{\zeta}=2.4 \times 10^{-10} \mathrm{~m}, \quad \beta_{s}=$ $\left.5 \times 10^{-9} \mathrm{~m}^{2} \mathrm{~s}^{-1} \mathrm{~V}^{-1}, \quad d=2 \times 10^{-5} \mathrm{~m}, \quad m=1.8, \quad \phi=0.2\right)$ has negligible effect upon the streaming potential for fluids with $C_{f}>0.01 \mathrm{M} \mathrm{NaCl}, \mathrm{pH} 5-8$. However, there is a significant reduction in the streaming potential for fluids where $C_{f}<0.01 \mathrm{M} \mathrm{NaCl}$, $\mathrm{pH}$ 5-8. Hence, the augmentation of this parameter has a similar effect as changes to rock microstructural properties, which enhance the role of surface conduction; both lead to a rock where the streaming-potential coefficient is affected by the surface conduction.

\section{The surface mobility}

We set the surface mobility to $\beta_{s}=5 \times 10^{-9} \mathrm{~m}^{2} \mathrm{~s}^{-1} \mathrm{~V}^{-1}$, which is between the value of $4 \times 10^{-9} \mathrm{~m}^{2} \mathrm{~s}^{-1} \mathrm{~V}^{-1}$ used by Revil et al. (1999a) in modeling the data of Watillon and de Backer (1970) and the value of $5.14 \times 10^{-9} \mathrm{~m}^{2} \mathrm{~s}^{-1} \mathrm{~V}^{-1}$ that Revil and Glover (1998) derived by fitting their theory to shaly sand data. It will be shown in the next paper of the series that the streaming-potential coefficient is extremely insensitive to changes in the surface mobility in this range. Unreasonably high surface mobilities are required (of the order of $10^{-5} \mathrm{~m}^{2} \mathrm{~s}^{-1} \mathrm{~V}^{-1}$ ) before there is a significant effect upon the modeled streaming-potential coefficient. It is also informative to note that these surface mobilities are approximately ten times less than the mobility of $\mathrm{Na}^{+}$in water $\left(\beta_{s}=\right.$ $5 \times 10^{-8} \mathrm{~m}^{2} \mathrm{~s}^{-1} \mathrm{~V}^{-1}$ ) according to Crow (1988) and Waxman and Smits (1968).

\section{COMPARISON WITH EXPERIMENTAL DATA}

\section{The effect of zeta-potential offset and permittivity}

The model has been implemented with the rock and fluid parameter values shown in Table 2. Initially we consider the streamingpotential coefficient and zeta potential generated by the model for three scenarios, which are shown in Figure 4. In each case, the theoretical curves for four $\mathrm{pH}$ values from $\mathrm{pH} 5$ to $\mathrm{pH} 8$ are shown together with the database of streaming-potential coefficient and zeta-potential experimental measurements that were collected by or made by Vinogradov et al. (2010) and Jaafar et al. (2009).

The first scenario (Figure $4 \mathrm{a}$ and $4 \mathrm{~b}$ ) uses a relative electric permittivity calculated from equation 5 and a zeta potential calculated from equation 16. This scenario represents the use of the theoretical model as described in Section 3. The relative electric permittivity depends upon both temperature and salinity, and for $T=25^{\circ} \mathrm{C}$ varies from 78.235 for $C_{f}=10^{-5} \mathrm{~mol} / \mathrm{L}$ to 24.675 for $C_{f}=10 \mathrm{~mol} / \mathrm{L}$. The modeled zeta potential (Figure $4 \mathrm{~b}$ ) is smaller than the measured values and becomes positive for low $\mathrm{pH}$ and at high salinity. This behavior causes the streaming-potential coefficient (Figure 4a) to become positive for $\mathrm{pH} 5$ and $\mathrm{pH} 6$ at high salinity, and ensures that the modeled streaming-potential coefficient is up to one order of magnitude too small for $C_{f}>1 \mathrm{~mol} / \mathrm{L}$ for $\mathrm{pH} 7$ and $\mathrm{pH} 8$.

The second scenario (Figure $4 \mathrm{c}$ and $4 \mathrm{~d}$ ) seeks to improve the fit of the model to the experimental data by introducing a constant 
zeta-potential offset $\zeta_{o}$, where equation 16 is replaced by $\zeta=\varphi_{d} \exp \left(-\chi_{\zeta} / \chi_{d}\right)+\zeta_{o}$, and retaining the variable permittivity calculated with equation 5 . The modeled zeta potential (Figure $4 \mathrm{~d}$ ) now agrees well with the measured values over the whole range of salinity, remaining negative throughout. This behavior also causes the streaming-potential coefficient (Figure 4a) to be modeled extremely well for all the $\mathrm{pH}$ values used in this work, and particularly well for high salinity $\left(C_{f}>1 \mathrm{~mol} / \mathrm{L}\right)$. While this approach is clearly successful, it represents an ad hoc addition to the model that is not supported theoretically. However, such a parameter has already been discussed in relation to the measurements at high salinity made by Jaafar et al. (2009).
The third scenario (Figure $4 \mathrm{e}$ and $4 \mathrm{f}$ ) arises from the possibility that the electric permittivity calculated with equation 5 might not be the most appropriate. A lower permittivity might be more appropriate, as we have already discussed in Section 3.2. However, the theoretical framework for providing it is not yet in place. Here we have chosen to replace the electric permittivity at all salinity with the value 20 . In reality, we would expect the appropriate value of electric permittivity to fall between the value calculated by equation 5 and the value five, which was the lowest value shown by Grahame (1950), and also to vary with salinity. A constant value of 20 has been used here to show the effect of a different electric permittivity within the model as simply as possible. Figure $4 \mathrm{f}$ shows the zeta

Table 2. The parameter values used in the modeling of the streaming-potential coefficient and zeta potential for the entire data set (Figures 5 and 6).

\begin{tabular}{|c|c|c|c|c|}
\hline Parameter & Symbol & Value or range & Units & Source \\
\hline \multicolumn{5}{|l|}{ Model variables } \\
\hline Temperature & $T$ & 25 & ${ }^{\circ} \mathrm{C}$ & Mean condition \\
\hline Pore fluid salinity & $C_{f}$ & $10^{-5}-3.98$ & $\mathrm{~mol} / \mathrm{L}$ & Varied between limits \\
\hline Pore fluid $\mathrm{pH}$ & $\mathrm{pH}$ & $6-8$ & $(-)$ & Varied between limits \\
\hline \multicolumn{5}{|l|}{ Fundamental constants } \\
\hline Dielectric permittivity in vacuo & $\varepsilon_{o}$ & $8.854 \times 10^{-12}$ & $\mathrm{~F} / \mathrm{m}$ & Lide (2009) \\
\hline Boltzmann's constant & $k_{b}$ & $1.381 \times 10^{-23}$ & $\mathrm{~J} / \mathrm{K}$ & Lide (2009) \\
\hline Charge on an electron & $e$ & $1.602 \times 10^{-19}$ & $\mathrm{C}$ & Lide (2009) \\
\hline Avogadro's number & $N$ & $6.022 \times 10^{+23}$ & $/ \mathrm{mol}$ & Lide (2009) \\
\hline \multicolumn{5}{|l|}{ Fluid parameters } \\
\hline Ionic mobility of $\mathrm{Na}+$ in solution & $\beta_{\mathrm{Na}+}$ & $5.20 \times 10^{-8}$ & $\mathrm{~m}^{2} / \mathrm{s} / \mathrm{V}$ & Crow (1988) \\
\hline Ionic mobility of $\mathrm{H}+$ in solution & $\beta_{\mathrm{H}+}$ & $3.63 \times 10^{-7}$ & $\mathrm{~m}^{2} / \mathrm{s} / \mathrm{V}$ & Crow (1988) \\
\hline Ionic mobility of $\mathrm{Cl}-$ in solution & $\beta_{\mathrm{Cl}-}$ & $7.90 \times 10^{-8}$ & $\mathrm{~m}^{2} / \mathrm{s} / \mathrm{V}$ & Crow (1988) \\
\hline Ionic mobility of $\mathrm{OH}-$ in solution & $\beta_{\mathrm{OH}-}$ & $2.05 \times 10^{-7}$ & $\mathrm{~m}^{2} / \mathrm{s} / \mathrm{V}$ & Crow (1988) \\
\hline Disassociation constant of water & $K_{w}$ & $6.72 \times 10^{-9}-9.22 \times 10^{-9}$ & $(-)$ & Calculated with equation 9 \\
\hline $\begin{array}{l}\text { Equilibrium constant for dissolution } \\
\text { of } \mathrm{CO}_{2} \text { in water }\end{array}$ & $p K_{1}$ & 7.53 & $(-)$ & Revil and Glover (1998) \\
\hline $\begin{array}{l}\text { Equilibrium constant for formation } \\
\text { of the carbonate ion in water }\end{array}$ & $p K_{2}$ & 10.3 & $(-)$ & Revil and Glover (1998) \\
\hline \multicolumn{5}{|l|}{ Rock/fluid interface parameters } \\
\hline Surface-site density & $\Gamma_{s}^{o}$ & 10 & sites $/ \mathrm{nm}^{2}$ & Adjusted to fit data \\
\hline $\begin{array}{l}\text { Binding constant for cation (sodium) } \\
\text { adsorption on quartz }\end{array}$ & $p K_{m e}$ & 7.5 & $(-)$ & Adjusted to fit data \\
\hline $\begin{array}{l}\text { Disassociation constant for } \\
\text { dehydrogenization of silanol }\end{array}$ & $p K_{(-)}$ & 7.1 & $(-)$ & Adjusted to fit data \\
\hline Shear-plane distance & $\chi_{\zeta}$ & $2.4 \times 10^{-10}$ & $\mathrm{~m}$ & Revil and Glover (1997) \\
\hline Surface conduction (proton) & $\Sigma_{s}^{\text {Prot }}$ & $2.40 \times 10^{-9}$ & $S$ & Revil and Glover (1997) \\
\hline Ionic Stern-plane mobility & $\beta_{\text {Stern }}$ & $5.00 \times 10^{-9}$ & $\mathrm{~m}^{2} / \mathrm{s} / \mathrm{V}$ & Revil and Glover (1997) \\
\hline \multicolumn{5}{|l|}{ Rock parameters } \\
\hline Grain size (diameter) & $d$ & $2 \times 10^{-7}-2 \times 10^{-4}$ & $\mathrm{~m}$ & Varied between limits \\
\hline Cementation exponent & $m$ & 1.80 & $(-)$ & Calculated $m=-\log F / \log \phi$ \\
\hline Formation factor & $F$ & 19.87 & $(-)$ & $\begin{array}{l}\text { St. Bees sandstone (mean) } \\
\text { (Jaafar et al., 2009) }\end{array}$ \\
\hline Porosity & $\phi$ & 0.19 & $(-)$ & $\begin{array}{l}\text { St. Bee's sandstone (mean) } \\
\text { (Jaafar et al., 2009) }\end{array}$ \\
\hline
\end{tabular}


a)
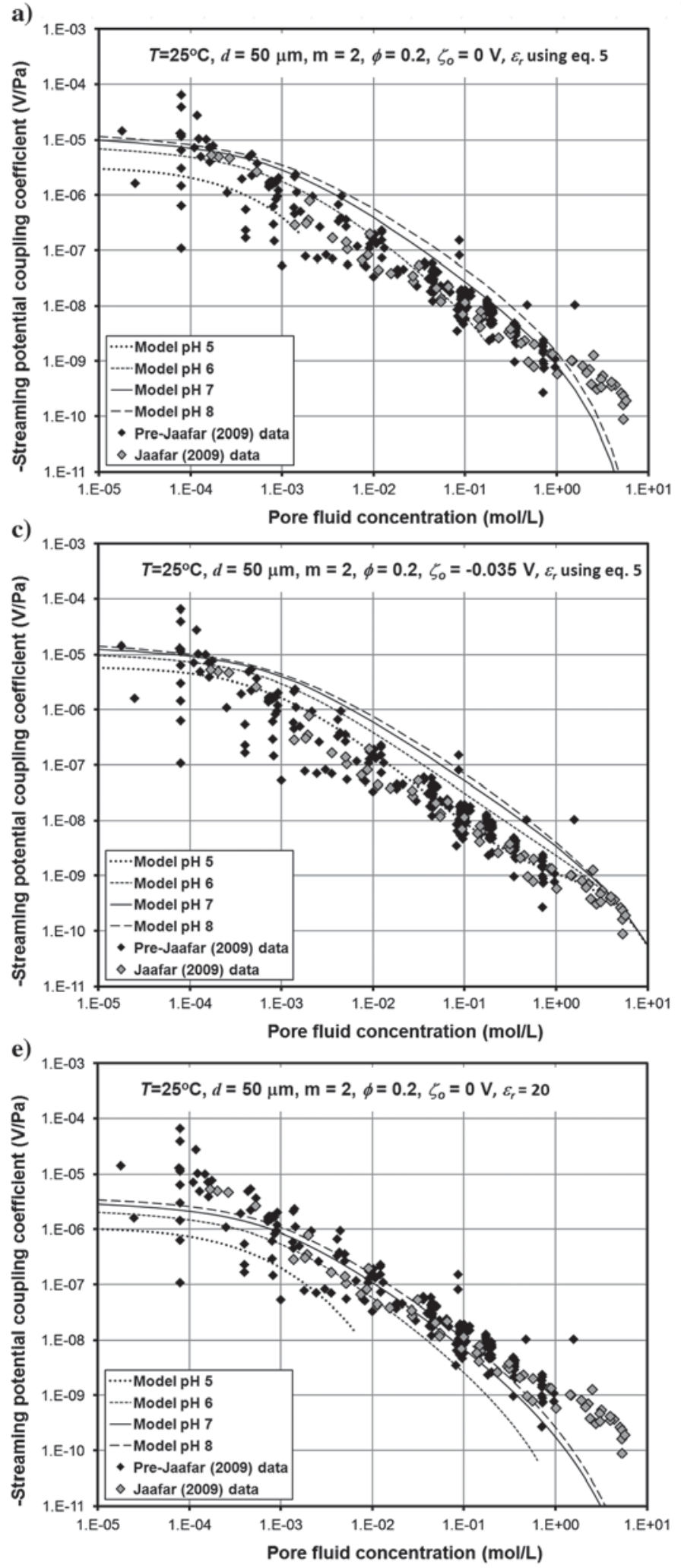

b)

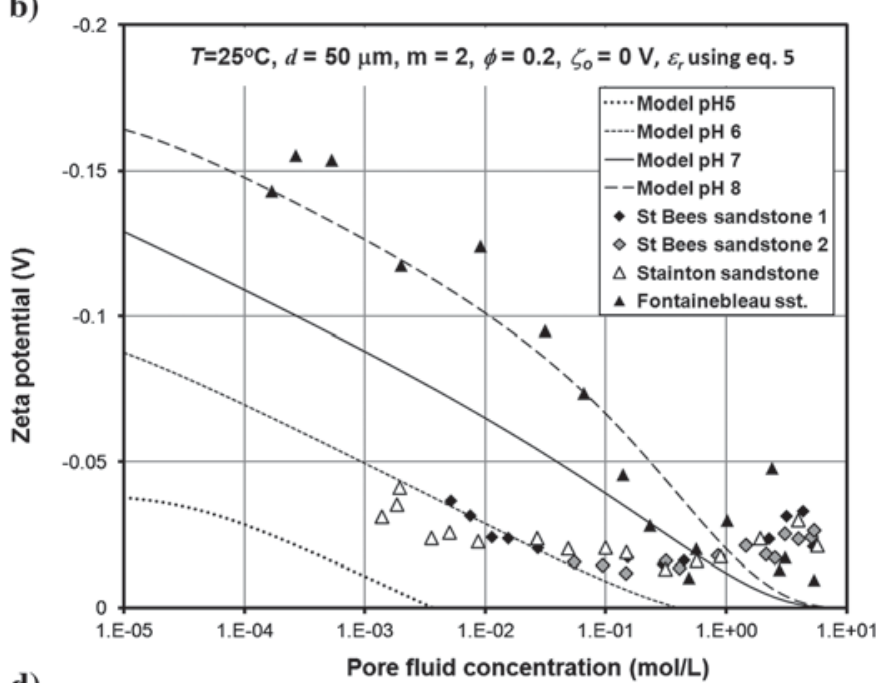

d)

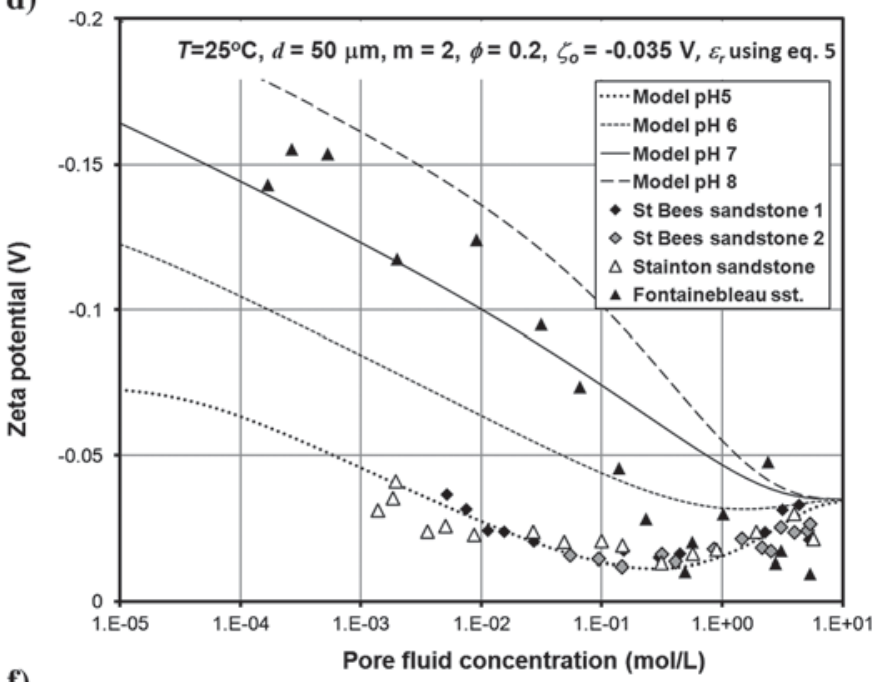

f)

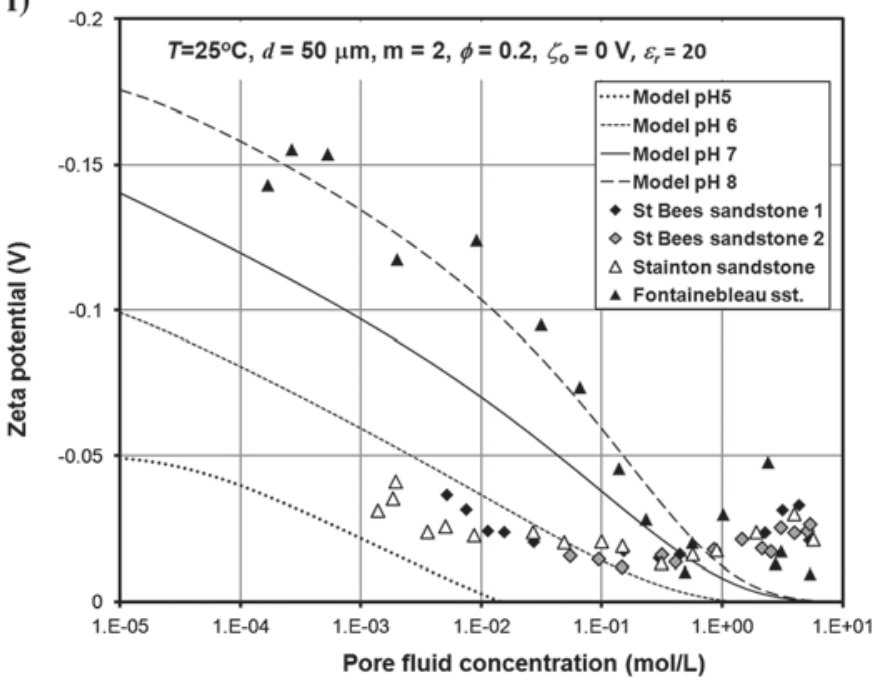

Figure 4. Pairs of modeled streaming-potential coefficient and zeta potential (curves) as a function of pore fluid salinity, for four $\mathrm{pH}$ values $\left(\mathrm{pH}=5,6,7\right.$, and 8), for three scenarios using different values of $\zeta_{o}$ and $\varepsilon_{r}:\left(\mathrm{a}\right.$ and b) $\zeta_{o}=0 \mathrm{~V}$ with $\varepsilon_{r}$ defined by equation 5, (c and d) $\zeta_{o}=-0.035 \mathrm{~V}$ with $\varepsilon_{r}$ defined by equation 5 , and (e and f) $\zeta_{o}=0 \mathrm{~V}$ with $\varepsilon_{r}=20$. In each case, $T=25^{\circ} \mathrm{C}, d=5 \times 10^{-5} \mathrm{~m}, \phi=0.2, m=2$ and $F=25$. The symbols show the same data set of experimental determinations as in Figure 1 (solid symbols; data from sources [1]-[11] in Figure 1, open symbols from Vinogradov et al. (2010) and Jaafar et al. (2009)). Other model parameters are given in Table 2. 
potential with no zeta-potential offset and a constant value of $\varepsilon_{r}=20$, while Figure $4 \mathrm{e}$ shows the modeled coupling coefficients using such a zeta potential. Figure $4 \mathrm{e}$ and $4 \mathrm{f}$ shows a superficial similarity to the curves produced with the variable electric permittivity. However, the zeta potentials are approximately $15 \mathrm{mV}$ more negative than the variable electric permittivity case, which improves the streaming-potential coefficient model, but not sufficiently to replace the use of a zeta-potential offset.

Hence, while the model is capable of reproducing the aggregated data fairly well, it is clearly very important that the origins of the zeta-potential offset or modifications to the model to make such an offset unnecessary are studied. In the following sections we use a zeta-potential offset where necessary, and calculate the relative electric permittivity with equation 5 .

\section{Streaming-potential coefficient}

The model has been implemented in two ways. First, with the mean rock and fluid parameter values shown in Table 2. In this case the model curves are compared with all the streamingpotential data in our database of silica-based porous media saturated with aqueous $\mathrm{NaCl}$, which we call the aggregated data set. These results (Figure 5 and Figure 6) are used to describe the general features of the model. Second, the model has been implemented for 12 individual types of porous media from various authors to examine the extent to which the model can reproduce the detailed variability of the experimental measurements. The individual fittings are shown in Figure 7 and their fitting parameters are given in Table 3.
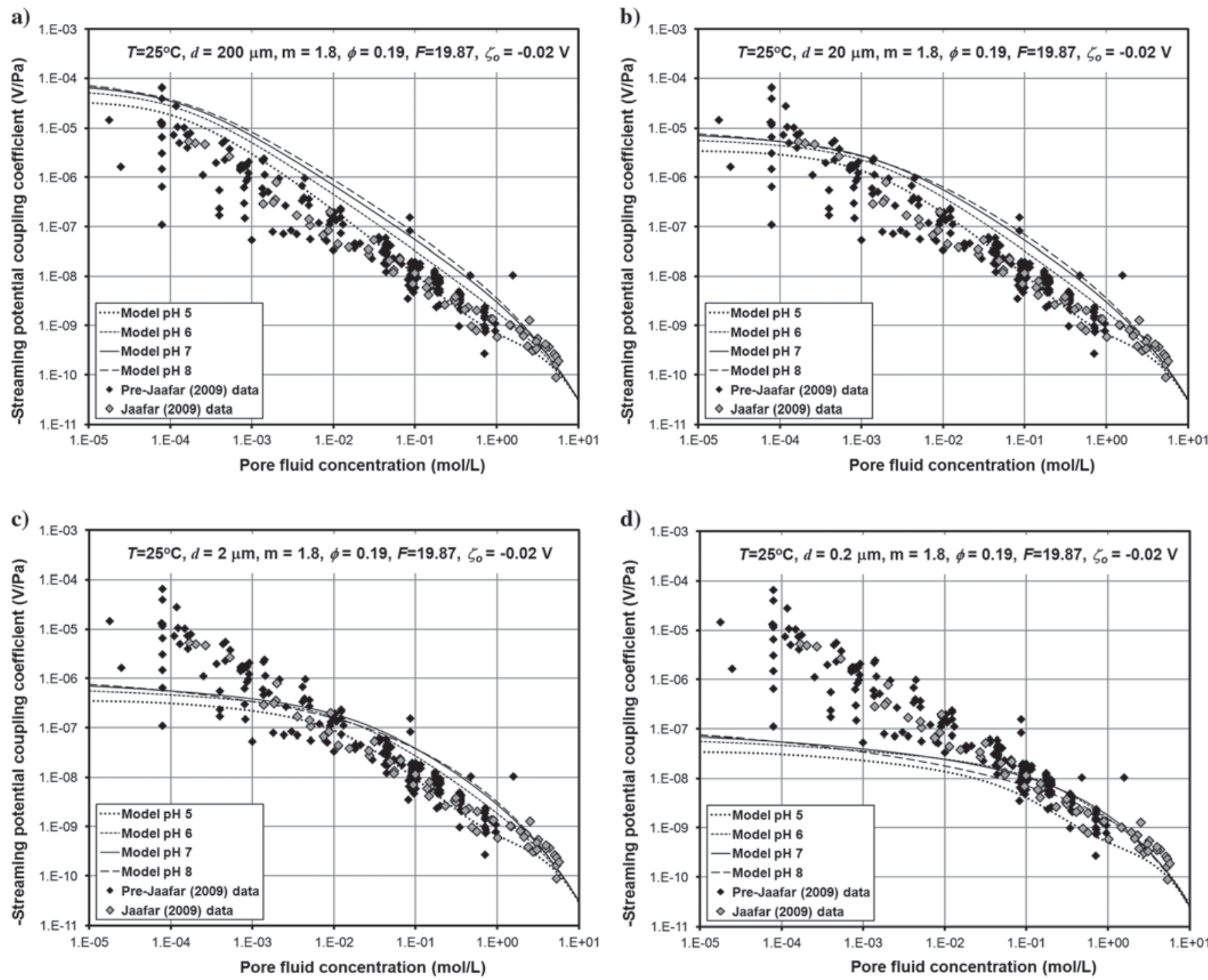

Figure 5. Modeled streaming-potential coefficient (curves) as a function of pore fluid salinity, for four $\mathrm{pH}$ values ( $\mathrm{pH}=5,6,7$, and 8 ), for four values of grain size (a) $2 \times 10^{-4} \mathrm{~m}$ (b) $2 \times 10^{-5} \mathrm{~m}$ (c) $2 \times 10^{-6} \mathrm{~m}$ (d) $2 \times 10^{-7} \mathrm{~m}$, and for a fixed porosity $(\phi=0.19)$, cementation exponent $(m=1.80)$ and formation factor $(F=19.87)$, which is that of the St. Bees sandstone (see Table 2$)$. The symbols show the same data set of experimental determinations as in Figure 1 (solid symbols; data from sources [1]-[11] in Figure 1, open symbols from Vinogradov et al. (2010) and Jaafar et al. (2009)). Other model parameters are given in Table 2. 
Streaming potential coefficient model compared with aggregated data

The results of modeling the aggregated data are shown in Figure 5 and Figure 6 for all the experimental data as a function of pore fluid concentration, for four values of $\mathrm{pH}(\mathrm{pH}=5,6,7$ and 8$)$, and as a function of either grain size or formation factor, respectively. The parameters used in the aggregated data fit are shown in Table 2. It is worthwhile noting that only three of these parameters are truly variable (viz., surface site density $\Gamma_{\mathrm{s}}^{\mathrm{o}}$, the binding constant for cation [sodium] adsorption on quartz $p K_{m e}$, and the disassociation constant for dehydrogenization of silanol $\left.p K_{(-)}\right)$. These were varied until the best fit to the data was attained, while respecting constraints imposed by independent measurements the parameters that have already been discussed previously as well as various limitations imposed by the physics of the system. The $\mathrm{pH}$ range that we have used here is sufficient to cover the range of $\mathrm{pH}$ present in most of the referenced experimental data (see Table 1). A model temperature of $25^{\circ} \mathrm{C}$ has been used for the modeling of the aggregated data, which represents the experimental conditions of most of the experimental data very well (see Table 1).

Because Figures 5 and 6 compare the modeled streamingpotential coefficient with the whole database, we need to use representative values for the microstructural parameters of the whole data set. We have chosen to use the rock parameters that were measured for the St. Bees sandstone used by Vinogradov et al. (2010). Hence, the fit to the St. Bees sandstone ought to be better than that for the other measurements.

It is clear that the model reproduces the main features of the aggregated data well in both Figure 5 and Figure 6. At high salinity, the fit is good and the model is not sensitive to varying the $\mathrm{pH}$ in the range $5<\mathrm{pH}<8$. The lack of sensitivity to $\mathrm{pH}$ at high salinity is due to the fact that the $\mathrm{NaCl}$ concentration is much greater a)

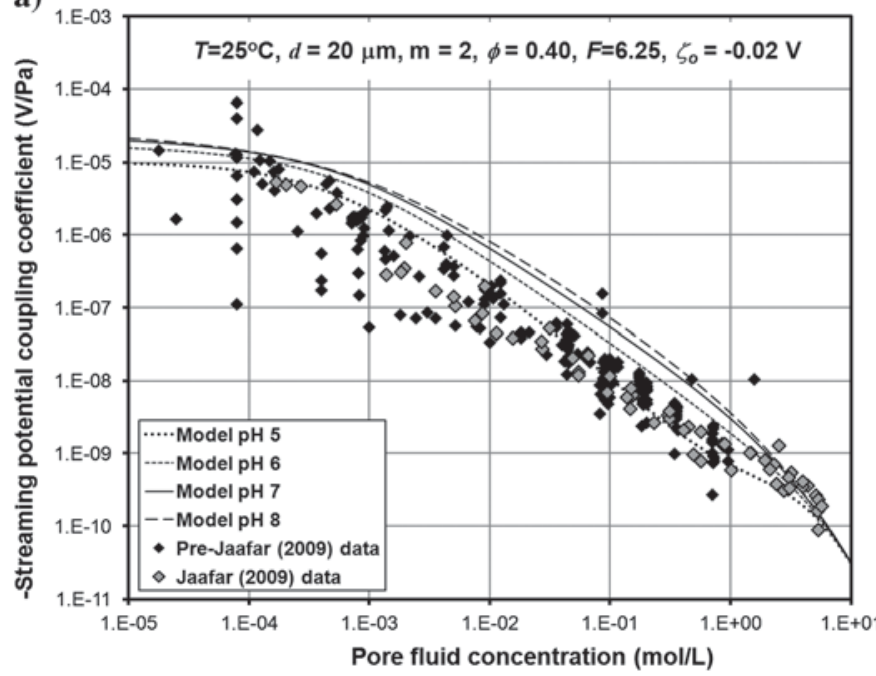

c)

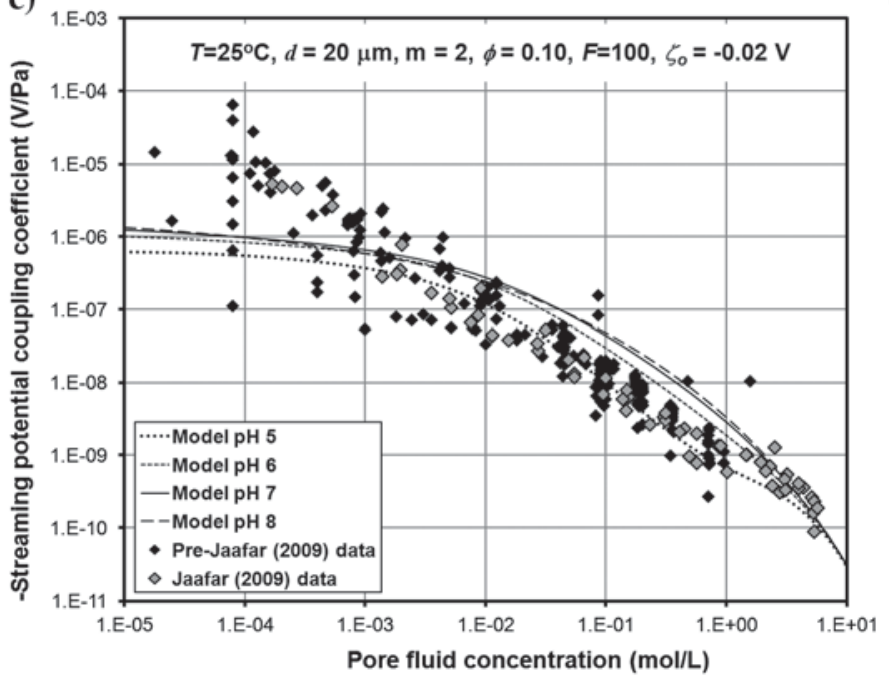

b)

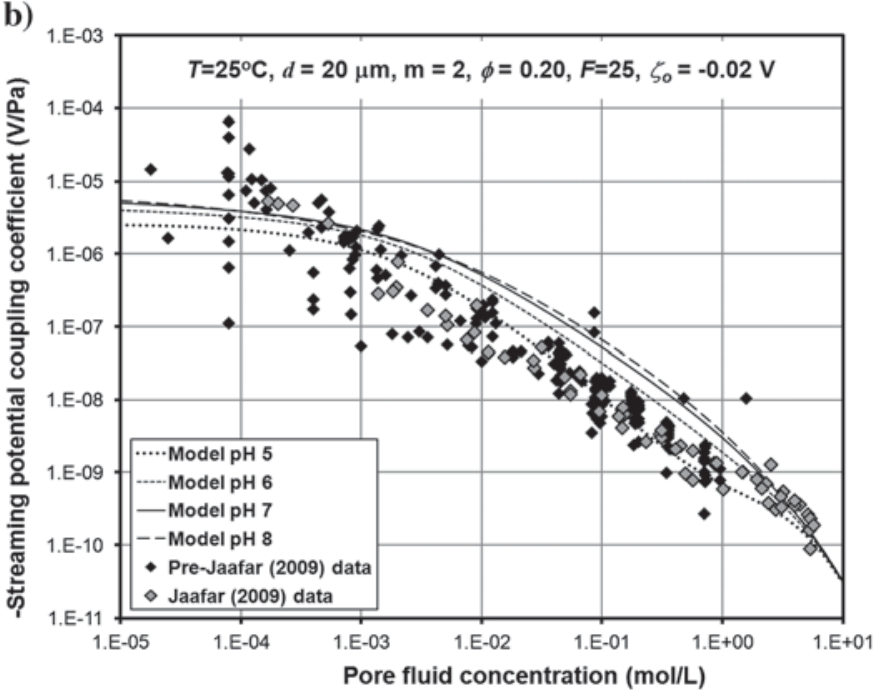

d)

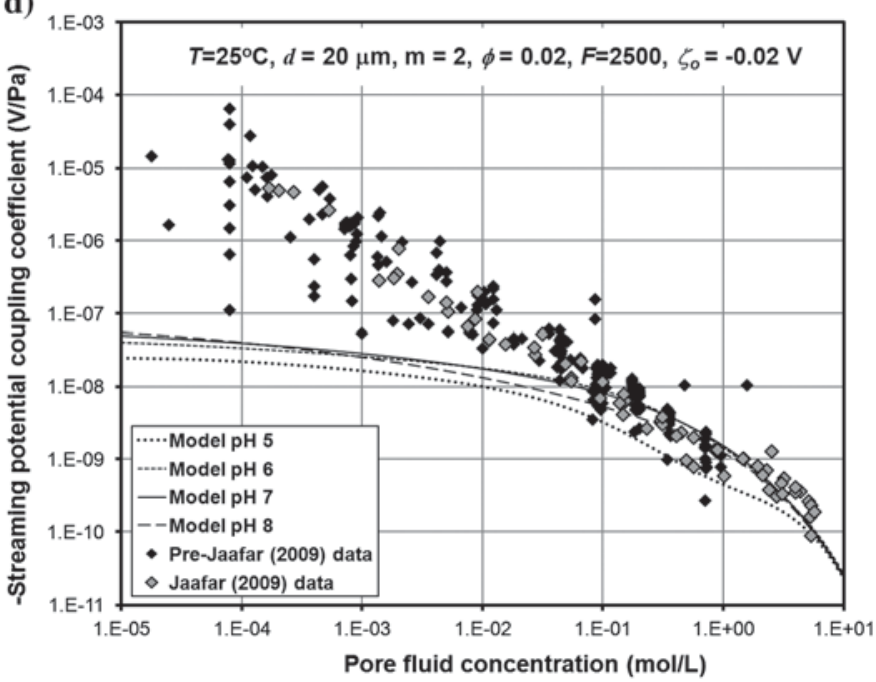

Figure 6. Modeled streaming-potential coefficient (curves) as a function of pore fluid salinity, for four $\mathrm{pH}$ values $(\mathrm{pH}=5,6,7$, and 8 ), and for four values of porosity and formation factor (a) $\phi=0.02, F=2500$ (b) $\phi=0.1, F=100$ (c) $\phi=0.2, F=25$ (d) $\phi=0.4, F=6.25$, each with a fixed cementation exponent $m=2$ and a fixed grain size $d=2 \times 10^{-5} \mathrm{~m}$. The symbols show the same data set of experimental determinations as in Figure 1 (solid symbols; data from sources [1]-[11] in Figure 1, open symbols from Vinogradov et al. (2010) and Jaafar et al. (2009)). Other model parameters are given in Table 2. 
a)

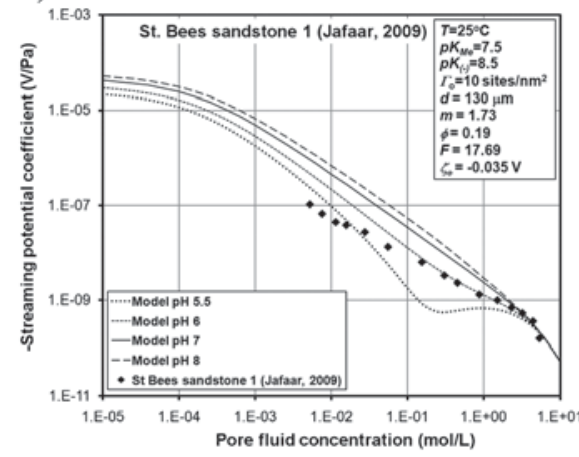

d)

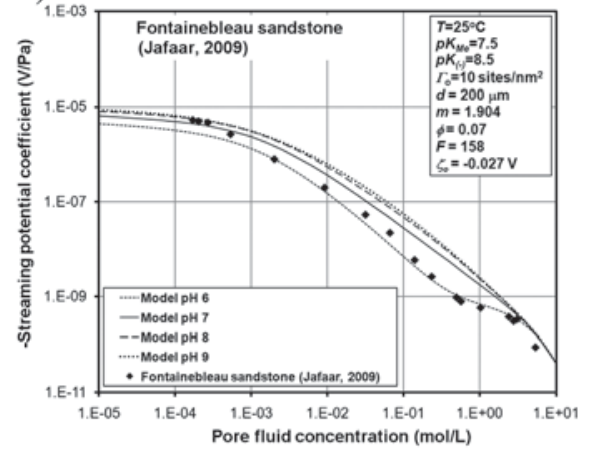

g)

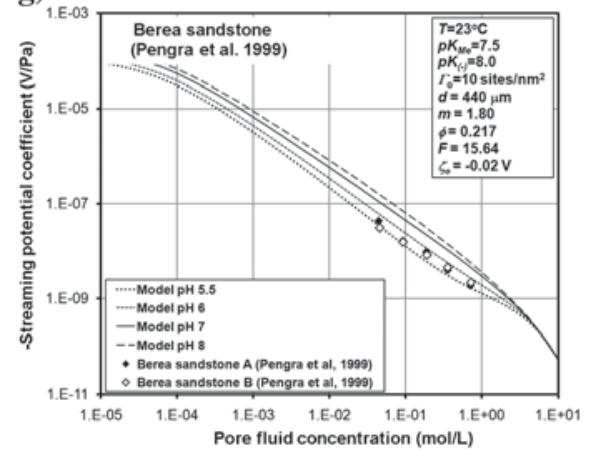

j)

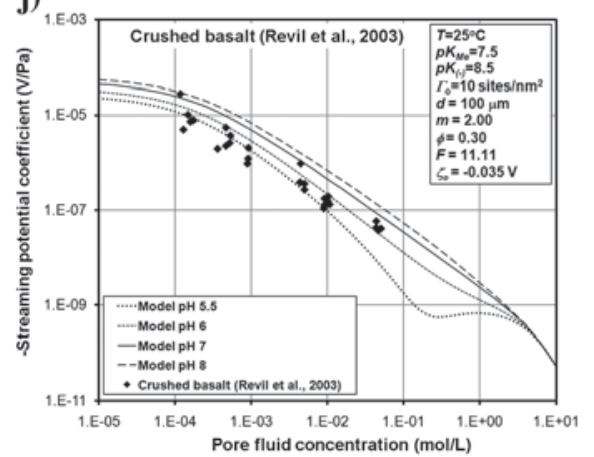

b)

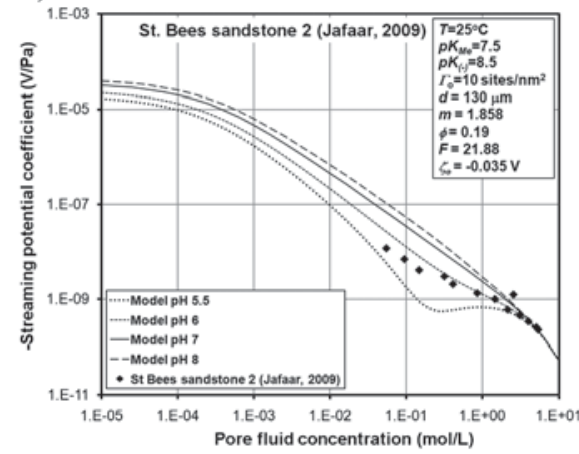

e)

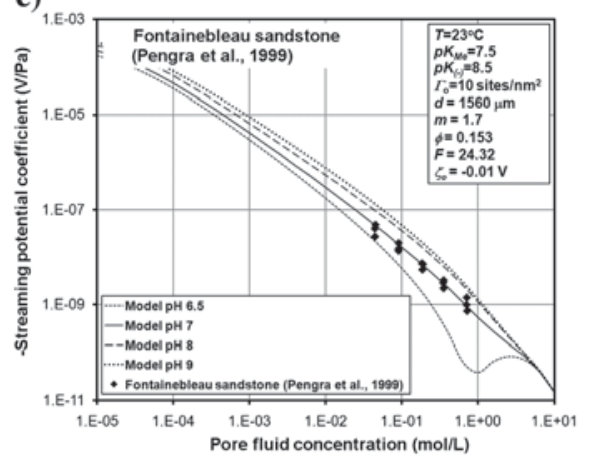

h)

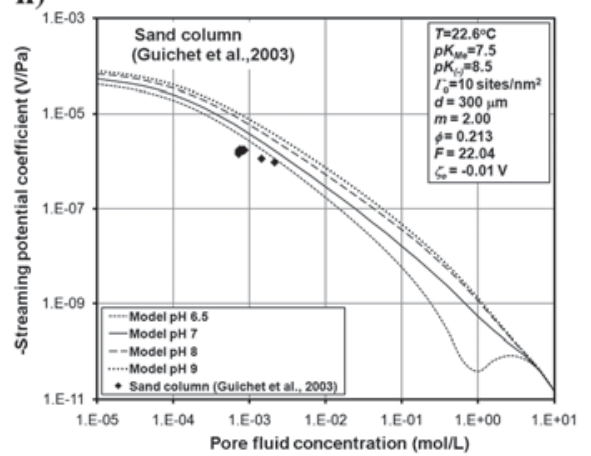

k)

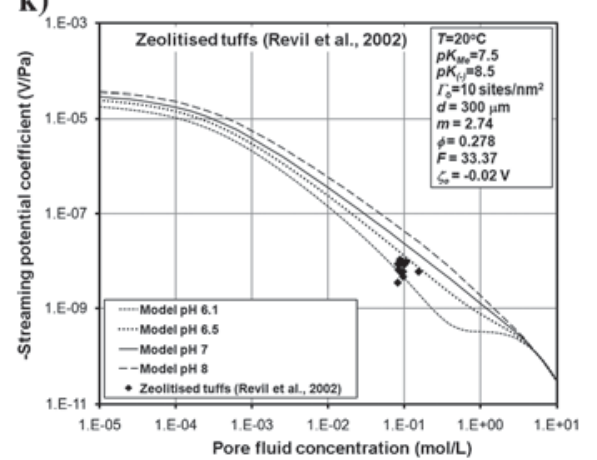

c)

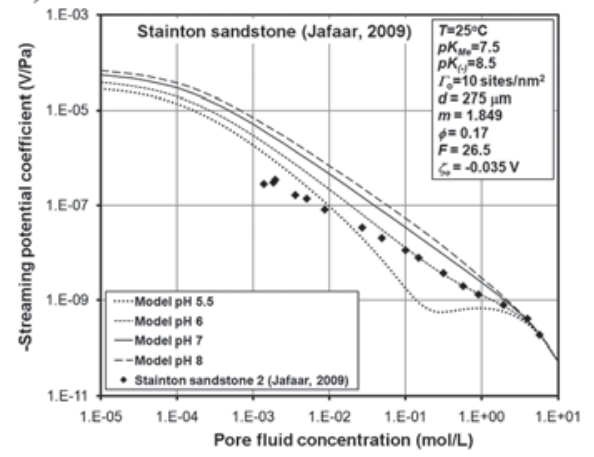

f)

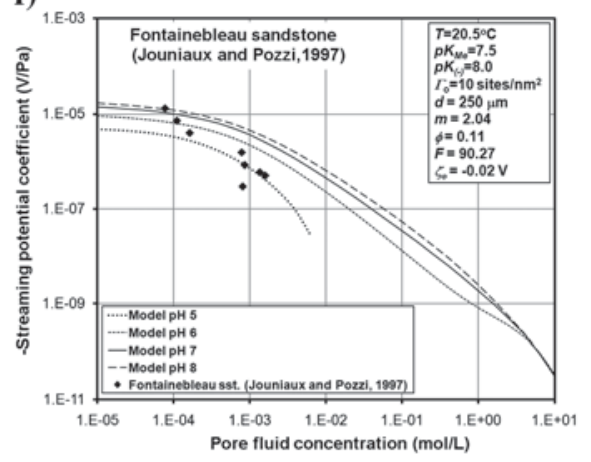

i)

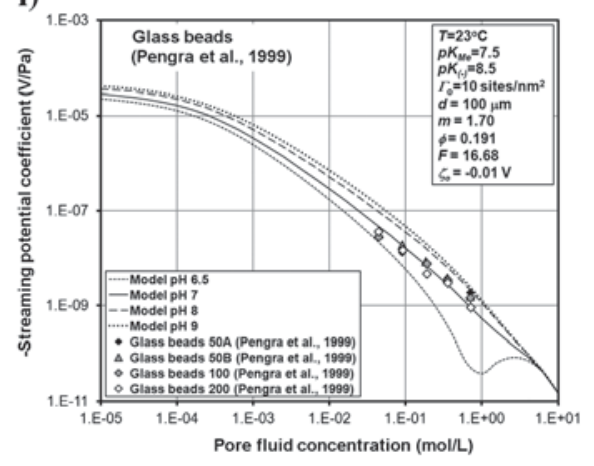

l)

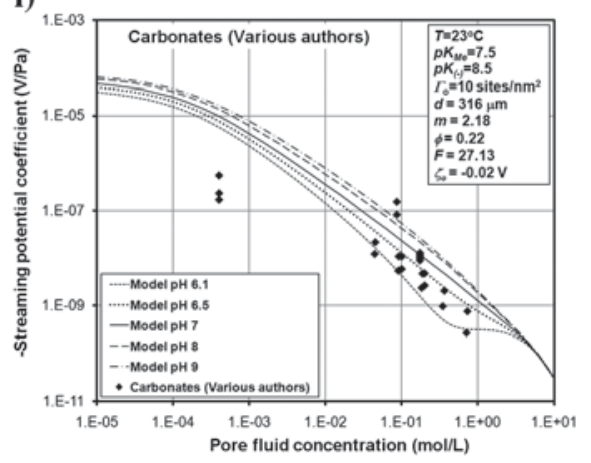

Figure 7. Modeled streaming-potential coefficient (curves) as a function of pore fluid salinity and pH, compared with the individual datasets from our database of experimental streaming-potential coefficient determinations (symbols). All model parameters are shown in Table 3. In this model there are 21 parameters, of which three are model variables (temperature, fluid concentration, and $\mathrm{pH}$ ), 11 are predefined by the electrochemistry of the fluid and fluid-mineral interface, and four are predefined by the rock microstructure. The model retains only three variable parameters $\left(\Gamma_{s}^{o}, p K_{(-)}, \zeta_{o}\right)$, which have only been allowed to vary within the bounds set out in the last section. (a) St. Bees sandstone (Vinogradov et al., 2010), (b) St. Bees sandstone (Vinogradov et al., 2010), (c) Stainton sandstone (Vinogradov et al., 2010), (d) Fontainebleau sandstone (Vinogradov et al., 2010), (e) Fontainebleau sandstone (Pengra et al., 1999), (f) Fontainebleau sandstone (Jouniaux and Pozzi, 1997), (g) Berea sandstone (Pengra et al., 1999), (h) Sand column (Guichet et al., 2003), (i) Glass beads (Pengra et al., 1999), (j) Crushed basalt (Revil et al., 2003), (k) zeolitized tuffs (Revil 2002; Revil et al., 2002), (1) carbonates (Sprunt et al., 1994; Li et al., 1995; Pengra et al., 1999; Revil and Cerepi, 2004). 


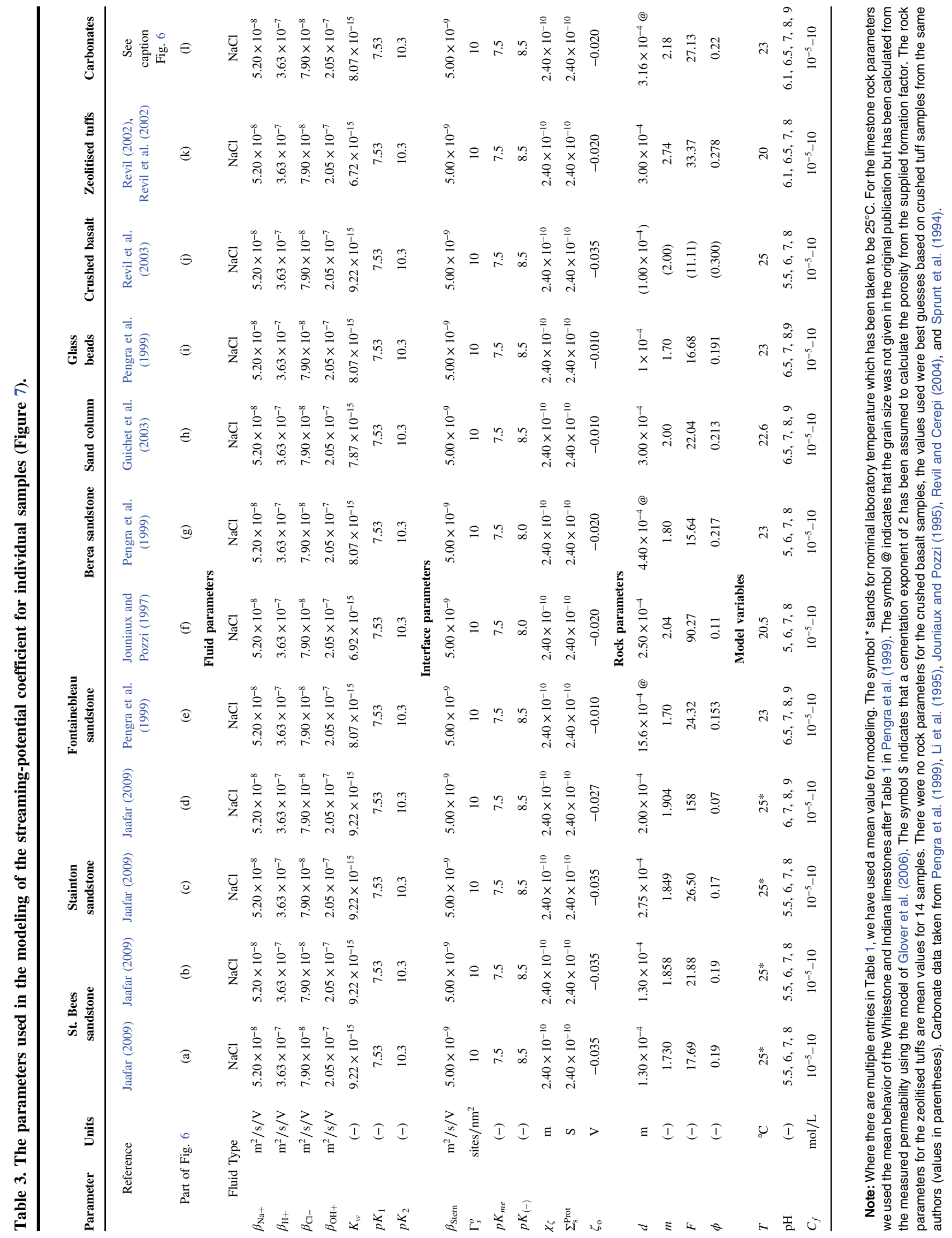


than the concentration of other ions in solution (i.e., $C_{f} \gg C_{a}+C_{b}+C_{H}^{+}+C_{O H}^{-}$), whereas the quality of the fit is due to the value $\zeta_{o}=-0.02 \mathrm{~V}$. At moderate salinity, the model has the same slope as the data, but slightly overestimates the experimental data due to our application of the zeta-potential offset to all salinities. At low salinity, the model is controlled by the rock microstructure as described below.

Figure 5 shows how reducing the grain size from $200 \mu \mathrm{m}$ to $0.2 \mu \mathrm{m}$ in decade steps reduces the streaming potential at progressively lower fluid concentrations, an effect that we will call flattening at low salinity. This effect has its origin in the value of the surface conductance and its expression via the surface conductance term in equation 22. The flattening of the theoretical curve at low salinity develops when the ratio of bulk pore fluid conductivity to the value of surface conductance is less than a value given by $\sigma_{f} / \Sigma_{s} \leq 6(F-1) / d$. An alternative way of interpreting the data is to say that rocks with small grain sizes have larger internal surface areas and correspondingly greater specific surface conductances than those with larger grain sizes. In these rocks the $6 \Sigma_{s}(F-1)$ term in equation 22 dominates the $d \sigma_{f}$ term, and the porous media's streaming-potential coefficient is controlled by surface conduction. There is clearly no effect at high salinity where the bulk fluid conductivity is always much larger than the specific surface conductance.

The flattening out at low salinity can also be achieved by varying the value of the surface conductance $\Sigma_{\mathrm{s}}$. In this case a higher surface conductance allows the $6 \Sigma_{s}(F-1)$ term in equation 22 to dominate the $d \sigma_{f}$ term leading to theoretical curves that resemble Figure 5d. To change the theoretical curves from those in Figure 5a to those in Figure $4 d$, while keeping the grain size constant, one needs to increase the surface conductance by about two orders of magnitude.

Figure 6 shows how increasing the formation factor porosity from 6.25 to 2500 also increases the flattening of the theoretical curves at low salinity. In this case the higher formation factors allow the $6 \Sigma_{s}(F-1)$ term in equation 22 to dominate the $d \sigma_{f}$ term. Because the formation factor depends on both the porosity and the cementation factor of the porous medium, we can say that the degree to which flattening at low salinity occurs also depends upon porosity and cementation exponent. Indeed the progressive flattening shown in each of the parts of Figure 6, respectively, could be caused by a porosities taking the values $\phi=0.4,0.2,0.1$, and 0.02 with a constant cementation exponent of $m=2$, or the cementation exponent taking the values $m=1.14,2,2.86$, and 4.86 with a constant porosity of $\phi=0.2$.

The formation factor is simply the inverse of the connectedness (Glover, 2009). Therefore, for highly connected pore structures with low formation factors (which implies larger porosities and/or small cementation exponents) there is little flattening out of the streaming-potential coefficient curve at low salinity because the specific surface conductance is relatively weak compared to the conduction through the bulk fluid. Conversely, for pore structures with low connectedness and high formation factors (implying small porosities and/or higher cementation exponents) flattening is well developed because the specific surface conductance dominates conduction through the rock.

Hence, between them, the surface conductance, grain size, porosity, cementation exponent, and formation factor control the size of the low-salinity streaming-potential coefficient. It is the variability of these parameters in the experimental data set that gives the data set its spread at low salinity.

Clay-rich rocks have (1) grain sizes that are significantly smaller than clean rocks, (2) surface conductances that are significantly greater than clean rocks, and (3) smaller connectednesses (high formation factors and cementation exponents) compared to clean rocks. All three properties ensure that $6 \Sigma_{s}(F-1) \gg d \sigma_{f}$ and hence provide theoretical streaming-potential coefficient curves that flatten out at low salinity like those shown in Figures 5d and 6d. Conversely clean rocks have larger grain sizes, smaller surface conductances, and higher connectednesses, where $6 \Sigma_{s}(F-1) \ll d \sigma_{f}$, and giving theoretical streaming-potential coefficient curves that do not flatten out at low salinity like those shown in Figures 5a and 6a.

In summary, Figures 5 and 6 show that the theoretical model conforms to the whole data set very well for salinity between $10^{-5}$ and $5 \mathrm{~mol} / \mathrm{L}$, $\mathrm{pH}$ between 5 and 8 for an experimental temperature of $25^{\circ}$ C. The model parameters (shown in Table 2) all lie within the reasonable bounds defined by the samples themselves or the bounds of experimental measurements by other studies as described in the section above, entitled Model Parameters.

\section{Streaming-potential coefficient model compared with individual data}

Although it is useful to see whether the model can fit the database of measurements as a whole, if the model works well, better fits should be possible for specific measurement sets (i.e., measurements that were made on the same rock sample or rock type under the same conditions). We have carried out the procedure of running the model for particular types of porous media where high quality streaming-potential coefficient measurements are available. This has been carried out for 12 sample types as a function of pore fluid concentration and for four or five values of $\mathrm{pH}$ in the range $5<\mathrm{pH}<9$, which includes the range of $\mathrm{pH}$ encountered in the experimental data. Figure 7 shows the modeled curves compared with the experimental data, and Table 3 shows the model parameters that were used in each case.

Once again the model performs very well, and in some cases conforms to the fine structure of the data in a manner that was not possible with the aggregated data. A good example of this is the fit to the Fontainebleau sandstone data measured by Vinogradov et al. (2010) (Figure $7 \mathrm{~d}$ ). Here the dip in the streaming-potential coefficient at about $0.5 \mathrm{~mol} / \mathrm{L}$ is followed extremely well by the theoretical model. Similar behavior is captured by the model for both of the St. Bees sandstones and the Stainton sandstones (Figure 7a, 7b, and 7c). It is also interesting to note that the values of surface site density $\Gamma_{\mathrm{s}}^{\mathrm{o}}=10$ sites $/ \mathrm{nm}^{2}, p K_{M e}=7.5, p K_{(-)}=8.5, \chi_{\zeta}=2.4 \times 10^{-10}$ and $\Sigma_{s}^{\text {prot }}=2.4 \times 10^{-9}$ are constant throughout all samples except one, indicating that the variability between the models is mainly controlled by the microstructural properties of the samples (porosity, cementation exponent and grain size), which are fixed by independent measurements available in the source literature.

The streaming-potential-coefficient behavior (on a double logarithmic scale) can be split into three parts: (1) an asymptote toward zero at high salinity, (2) a central linear portion, and (3) a flattening of the curve at low salinity. We discuss each of these regimes separately below.

Although only one source (Vinogradov et al., 2010; Jaafar et al., 2009) has published high salinity $\left(C_{f} \geq 1 \mathrm{~mol} / \mathrm{L}\right)$ streamingpotential coefficient data, it did provide data on four samples of 
three different rock types and for 22 different salinities. All of these data show a continuation of the decrease of streamingpotential coefficient with salinity on a log-log scale reaching values of about $10^{-10} \mathrm{~V} \mathrm{~Pa}^{-1}$ at the saturation limit $(6.34 \mathrm{~mol} / \mathrm{L})$. The model predicts that the streaming-potential coefficient follows the experimental data very well, also reaching values of about $10^{-10} \mathrm{~V} \mathrm{~Pa}^{-1}$ at the saturation limit, but only when we set the zeta-potential offset to -0 . V (Figure $6 a, 6 b, 6 c$, and $6 d$ ).

At moderate salinity, we have already seen that the model agrees well with the experimental data set taken as a whole (Figures 5 and 6), bearing in mind the differences in rock microstructure and in fluid $\mathrm{pH}$ that exist among the data. However, when the model is used with individual rock types (Figure 7), it agrees even better with the experimental data. In the interval $10^{-3}<C_{f}<1 \mathrm{~mol} / \mathrm{L}$, the model fits the experimental data points very well for all 12 parts of Figure 7.

At low salinity there is a greater variability in the streamingpotential coefficient measurements as we have discussed previously. Figures 5 and 6 has already shown that all of these behaviors can be reproduced by the theoretical model by varying any combination of the grain size, the formation factor, or the surface conductance. Figure 7 shows that the low salinity behavior for individual rock types is reproduced well by the model for most of the rock types. There are three samples of carbonates that do not conform to the model, which represent three deformation states of one sample of limestone from Jouniaux and Pozzi (1995b). If the model is rerun with sample-specific parameters taken directly from Jouniaux and Pozzi (1995b) or calculated from parameters in that paper using the technique of Glover et al. (2006) (i.e., $\phi=0.37, m=1.21, F=3.3$, and $d=9.48 \mu \mathrm{m}$ ), the curves still do not fit the data. However, perhaps it is hardly surprising because the model is specific to silica-based mineralogies and is being applied to carbonates here.

\section{The zeta-potential behavior}

Once again the model has been implemented in two ways. First, with the mean rock and fluid parameter values shown in Table 2, in which case the model curves are compared with the aggregated zeta-potential data for silica-based porous media and a solution of $\mathrm{NaCl}$ (Figure 8). Second, the model has been implemented for 10 individual types of porous media from various authors to examine to what extent the model can reproduce the detailed variability of the experimental measurements. The individual fittings are shown in Figure 9 and their fitting parameters are given in Table 4.

\section{Zeta-potential model compared with aggregated data}

Calculation of the zeta potential is a part of the process of calculating the streaming-potential coefficient that uses a reduced set of modeling parameters. As far as this model is concerned, the zeta potential is not affected by the microstructural properties of the rock. That is to say, the model treats the zeta potential as the property of the rock-fluid interface and assumes that any changes to the rock microstructure do not appreciably change the zeta potential of the rock. This assumption is reasonable providing the flow through the rock occurs at sufficiently low Reynolds numbers that the position of the shear plane is not affected by turbulent flow caused by a combination of a tortuous pore network and a high flow rate.
Figure 8 shows that the curves for the theoretically modeled zeta potential vary considerably and are highly sensitive to changes in $\mathrm{pH}$. The overall trend for all the $\mathrm{pH}$ values modeled here, is for the negative zeta potential to decrease exponentially with increasing pore fluid concentration until the imposed zeta-potential offset value (here $\zeta_{o}=-0.035 \mathrm{~V}$ ). This behavior is in agreement with the general trend in the experimentally derived zeta-potential values from the aggregated database (symbols). For $\mathrm{pH}$ less than about $\mathrm{pH} 6$, the exponential decrease with increasing salinity stops at about $0.01 \mathrm{~mol} / \mathrm{L}$ and is replaced by zeta potentials that increase (become more negative) until the highest saturations are reached. This behavior results in a minimum in the zeta-potential curve between 0.01 and $0.1 \mathrm{~mol} / \mathrm{L}$. Such minimums in the zeta-potential behavior at high salinity have also been observed in zeta potentials derived from experimental measurements, notably by Vinogradov et al. (2010) and Jaafar et al. (2009) and apparent in Figure 8 as the data shown with gray symbols. The higher $\mathrm{pH}$ values also have a flattening of their curves at very low salinity, such as in the curve for $\mathrm{pH}$ 4.5. This behavior has also been observed in zeta potentials derived from experimental measurements; the experimental data which agree well with the theoretical curve for $\mathrm{pH} 4.5$ in Figure 8 is that from Lorne et al. (1999).

\section{Zeta-potential model compared with individual data}

Figure 9 shows modeling of the zeta potential for ten individual measurements; (1) St. Bees sandstone 1 ( NaCl, pH 6-8, Vinogradov et al., 2010), (2) St. Bees sandstone 2 (NaCl, pH 68, Vinogradov et al., 2010), (3) Stainton sandstone ( $\mathrm{NaCl}, \mathrm{pH} 6-$ 8, Vinogradov et al., 2010), (4) Fontainebleau sandstone ( $\mathrm{NaCl}$, pH 6-8, Vinogradov et al., 2010), (5) glass beads ( $\mathrm{NaCl}, \mathrm{pH}$ 5.6-5.9, Bolève et al., 2007), (6) silica beads ( $\mathrm{NaCl}, \mathrm{pH} 7$, Gaudin and Fuerstenau, 1955), (7) silica beads ( $\mathrm{NaCl}, \mathrm{pH} 2-10, \mathrm{Li}$ and de Bruyn, 1966), (8) silica beads ( $\mathrm{NaCl}, \mathrm{pH} 7$, Kirby and Hasselbrink, 2004), (9) quartz, vitreous silica, high silica glass and borosilicate glass ( NaCl, pH 5-6, Jednacak and Pravdic, 1974), and (10) sandstone (KCl, pH 6-7, Alkafeef and Alajmi, 2006). In each case,

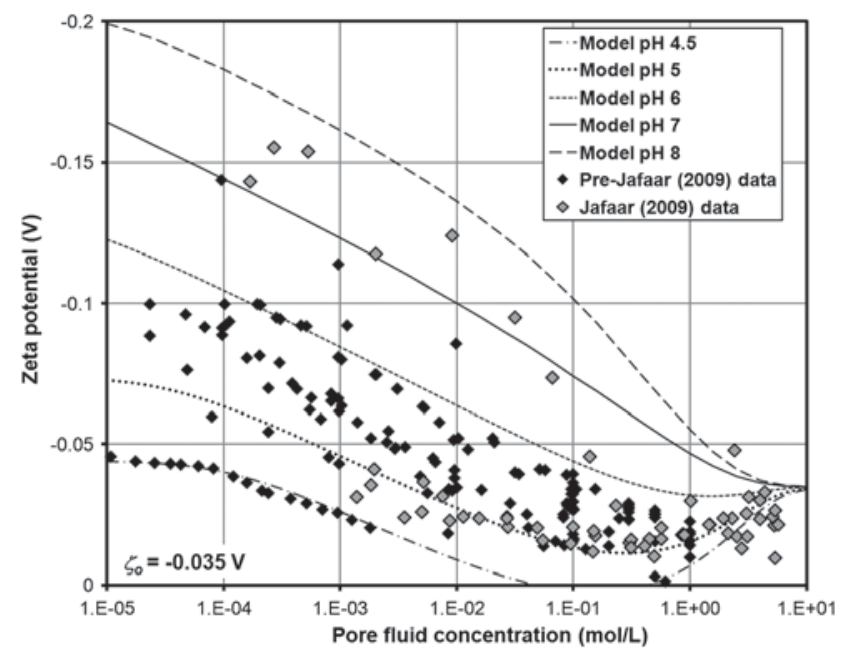

Figure 8. Modeled zeta potential (curves) as a function of pore fluid salinity for $5 \mathrm{pH}$ values $(\mathrm{pH}=4.5,5,6,7$, and 8$)$. The symbols show the whole data set of experimental determinations (same as in Figure 2). Model parameters are given in Table 2. The model is independent of rock microstructural parameters. 

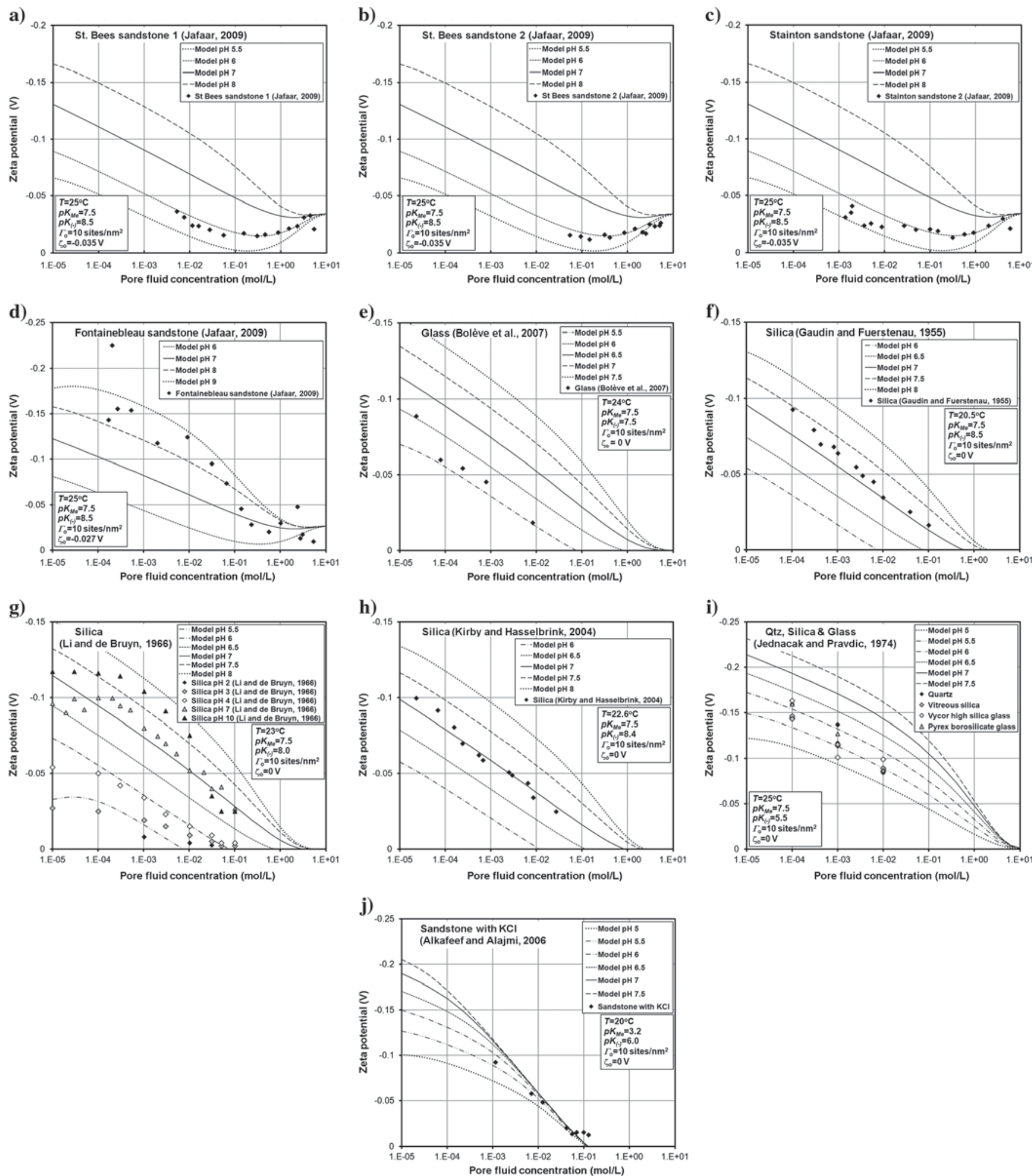

Figure 9. Modeled zeta potential (curves) as a function of pore fluid salinity and $\mathrm{pH}$, compared with the individual datasets from our database of experimental streaming-potential coefficient determinations (symbols). All model parameters are shown in Table 4. In this model there are 17 parameters, of which three are model variables (temperature, fluid concentration and $\mathrm{pH}$ ), and 11 are predefined by the electrochemistry of the fluid and fluid-mineral interface. There are no rock parameters because there is no influence from the rock microstructure. The model retains only three variable parameters $\left(\Gamma_{s}^{o}, p K_{(-)}, \zeta_{o}\right)$, which have only been allowed to vary within the bounds as in Figure 7. (a) St. Bees sandstone (Vinogradov et al., 2010), (b) St. Bees sandstone (Vinogradov et al., 2010), (c) Stainton sandstone (Vinogradov et al., 2010), (d) Fontainebleau sandstone (Vinogradov et al., 2010), (e) glass beads (Bolève et al., 2007), (f) silica (Gaudin and Fuerstenau, 1955), (g) silica (Li and de Bruyn et al., 1966), (h) silica (Kirby and Hasselbrink, 2004), (i) silica (Jednacak and Pravdic, 1974), (j) sandstone with KCl (Alkafeef and Alajmi, 2006). 


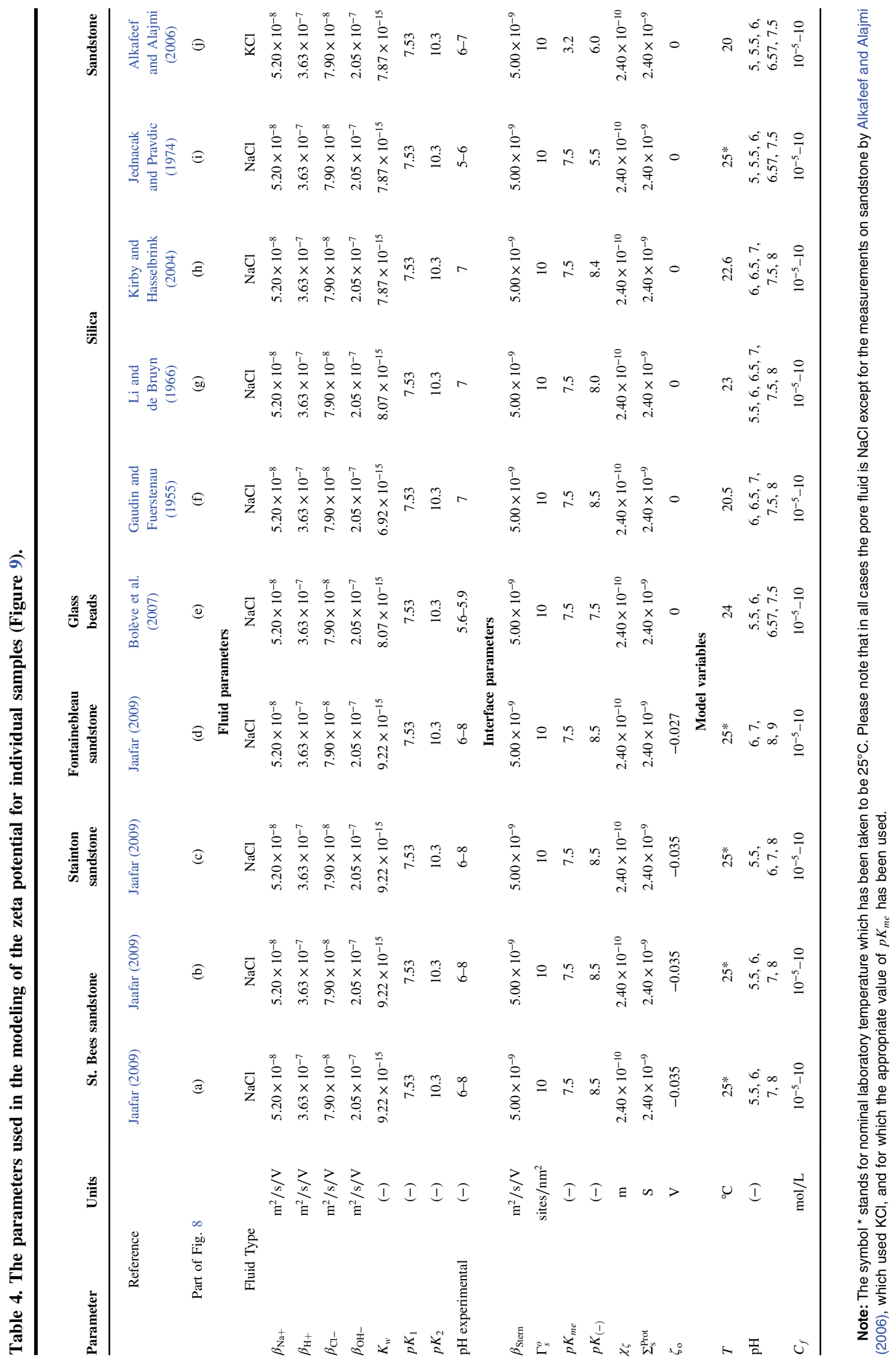


modeling has been carried out as a function of pore fluid salinity and $\mathrm{pH}$. The actual experimental temperature has been used for the modeling of the individual data sets, and we have attempted to provide theoretical curves for all the experimental range of $\mathrm{pH}$ quoted by the authors of the experimental works. However this has not been possible for $\mathrm{pH}$ less than $\mathrm{pH} 4.5$, for which certain fundamental assumptions that contribute to our theoretical model break down. The model parameters for the individual parts of Figure 9 are shown in Table 4. It should be noted that the pore fluid is $\mathrm{NaCl}$ in all cases except that given in Figure 9j, for which $\mathrm{KCl}$ was used.

All the individual fits show an exponential decrease in the zeta potential with salinity in the range $10^{-5}$ to $0.1 \mathrm{~mol} / L$, which is well followed by the model presented in this paper. The gradient of this decrease varies little and seems to be controlled in part by the value of $p K_{M e}$. It is interesting to note that Figure $9 \mathrm{a}-9 \mathrm{i}$, uses a constant value of $p K_{M e}=8.5$, which is within the experimental range measured by other authors (see Section 4.2). However, the data in Figure $9 \mathrm{j}$ are for sandstone saturated with $\mathrm{KCl}$ (Alkafeef and Alajmi, 2006), and follow a significantly steeper gradient than the other parts of the figure. Nevertheless, these data can be fitted well by the model if we set $p K_{M e}=3.2$, which is the experimental value found for a silica surface in equilibrium with a solution of $\mathrm{KCl}$ by Scales et al. (1990). Hence, the value of $p K_{M e}$ seems to control the rate with which the zeta potential diminishes as salinity increases.

The first four parts of Figure 9 contain data that were measured with $\mathrm{NaCl}$ solutions of very high salinity by Vinogradov et al. (2010) and Jaafar et al. (2009). Their data show that for $C_{f}>0.1 \mathrm{~mol} / \mathrm{L}$ the decrease in zeta potential with increasing salinity does not continue. Instead, the zeta potential seems to reverse direction and increase slightly, causing a shallow minimum in the zeta-potential curve at about $0.3 \mathrm{~mol} / \mathrm{L}$. It is interesting to note that this behavior can also be followed by our model providing we set $\mathrm{pH}=6$ for the samples shown in Figure 9a, 9b, and 9c, and $\mathrm{pH}=8$ for the Fontainebleau sandstone data shown in Figure 9d, and we include a nonzero zeta-potential offset. These $\mathrm{pH}$ values may be consistent with comments in Vinogradov et al. (2010), which state that the $\mathrm{pH}$ in their measurements varied between pH 6 and pH 8. However, Vinogradov et al. (2010) are not specific about which $\mathrm{pH}$ refers to which samples and which salinities. Overall, it is clear that the zeta potential is so sensitive to $\mathrm{pH}$ that experimentalists must seek to measure the $\mathrm{pH}$ of their process fluids immediately that they exit the sample, and then to report the $\mathrm{pH}$ together with each measurement of streaming-potential coefficient or zeta potential.

\section{Zeta-potential dependence on rock microstructure}

It should be noted that it is generally considered that there is no dependence of the zeta potential on the microstructural properties of the rock at low salinity, unlike for the streaming-potential coefficient because the zeta potential is not affected by changes in the surface conductance of the rock. However, there is a theoretical possibility that the zeta potential may be affected by the rock microstructure at extremely low salinity. If we remember that the zeta potential is the electrical potential on the shear plane, and that the thickness of the double layer increases as the pore fluid salinity decreases, it becomes apparent that at low salinity a perturbation of the position of the shear plane (i.e., increasing $\chi_{\zeta}$ ) by fast moving fluid flow caused by constrictions in the pore microstructure would give rise to a nonnegligible reduction in the potential at the shear plane.
Whether such a local effect would be measureable is debatable, and there are no experimental indications that are consistent with such behavior. If such an effect were to be observable, there would be a similar reduction in zeta potential upon increasing the flow rate in a porous medium. Data to test this are difficult to obtain. The effect is not seen in the data of Glover and Déry (2010). It is worth noting that this effect is different from that discussed by Crespy et al. (2007), where the change in apparent zeta potential with flow rate is caused by an oversimplified method for calculating the zeta potential from experimental data.

\section{Use of the model with clay-rich rocks}

This work has not explicitly considered clay-rich rocks for two reasons. First, some of the equations used in the model have been developed specifically for a silica surface. Second, the database with which the model has been compared is for various silica-based mineralogies. However, many parts of the model are compatible with rocks that contain clay minerals.

There are at least two ways in which the presence of clays would affect the modeling. First, due to surface complexation reactions; clay minerals undergo different surface complexation reactions than silica (e.g., Revil and Leroy, 2001), which lead to zeta potentials for kaolinite, for example, in the range $-15 \mathrm{mV}$ to $-30 \mathrm{mV}$ for $5<\mathrm{pH}<8$ and $C_{f}=2 \times 10^{-3} \mathrm{~mol} / \mathrm{L}$ (Revil and Leroy, 2001). By contrast, values in the range $-40 \mathrm{mV}$ to $-160 \mathrm{mV}$ are representative of silica in the same range of $\mathrm{pH}$ and $C_{f}$. The lower zeta potentials generated by clays leads to a decrease in the modeled streaming-potential coefficient by a factor of about three for all salinities.

This model can be converted for use with clay-rich rocks by incorporating the techniques given in Revil and Leroy (2001) to provide a more appropriate zeta potential. A quick and dirty approximation would be to divide the zeta potential calculated with this model by up to five depending on the volume of clay present and the manner of its distribution (i.e., if the clays coat the silica grains they will have a larger effect than if distributed uniformly

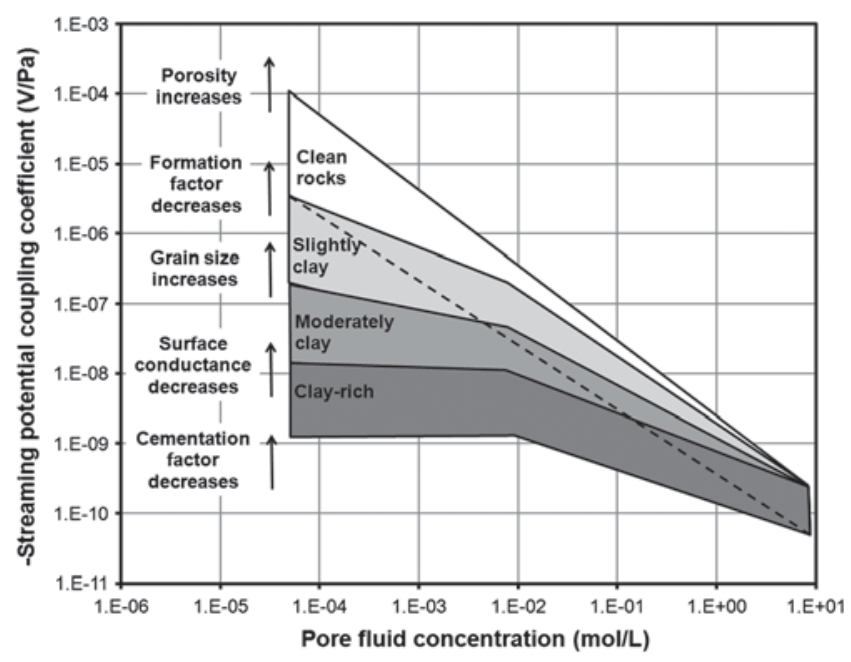

Figure 10. Schematic diagram of the streaming-potential coefficient as a function of pore fluid concentration for porous media containing different amounts of clay minerals. 
though the matrix). This reduced zeta potential could then be used to calculate the streaming-potential coefficient in the normal way.

The second way that clays affect the streaming-potential coefficient relates to their microstructure. We have already seen in Section 5.2.1 that clay-rich rocks have grain sizes that are significantly smaller, surface conductances that are significantly greater, and connectednesses that are much smaller than clean rocks. These three differences all lead to a flattening out of the streaming-potential coefficient values at low salinity. These effects are already built into our model, and are significant at low salinity, leading to variations of up to four orders of magnitude at $C_{f}=10^{-4} \mathrm{~mol} / \mathrm{L}$, but are negligible for $C_{f}>1 \mathrm{~mol} / \mathrm{L}$.

Figure 10 shows the effect of the presence of clays on the streaming-potential coefficient in a schematic way. Each of the shaded regions shows the approximate values of streaming-potentialcoupling coefficient as a function of pore fluid concentration within the range $5<\mathrm{pH}<9$. It should be noted that there is a significant overlap between the regions especially at high salinity where the effect of the clays upon the overall streaming-potential coefficient is negligible. The five factors with arrows on the left hand side show how the streaming potential of a given rock would change if that parameter were to vary.

\section{CONCLUSIONS}

We have described a theoretical method for calculating the Sternplane potential, zeta potential, surface conductance and streamingpotential coefficient of reservoir rocks and other porous media and compared it to an experimental data set of 290 streaming-potentialcoefficient measurements and 269 zeta-potential measurements obtained experimentally for 17 matrix-fluid combinations (e.g., sandstone saturated with $\mathrm{KCl}$ ) and using data from 29 publications.

The comparison shows that the theoretical model fits the experimental data well for reasonable values of its input parameters that are supported by independent measurements or theory. In addition, the model can reproduce variations in the data at low salinity that are associated with the development of surface conduction. Consequently, the low salinity behavior of the streaming-potential coefficient is sensitive to changes in the microstructure of the rock, particularly the grain size, cementation exponent, formation factor and porosity.

The basic theoretical model predicts zeta potentials and streaming-potential coefficients that can become positive at high salinity for some values of $\mathrm{pH}$ and $p K_{(-)}$. The experimental data show no positive values, with the zeta potential either becoming constant at about $-20 \mathrm{mV}$ or becoming slightly more negative after a maximum at about $0.3 \mathrm{~mol} / \mathrm{L}$, and the streaming-potential coefficient continuing to become less negative, but remaining negative. This effect has been attributed to diffuse layer charge density saturation when the diffuse layer thickness approaches the diameter of the counterions. We have implemented a zeta-potential offset to the model, which has allowed the high salinity measurements to be incorporated within the model heuristically, and has enabled the model to reproduce the streaming-potential coefficient and zetapotential measurements at high salinity. It should be noted that the physics that underlies the need for such an ad hoc parameter needs to be understood as soon as possible, and would represent the best improvement to the model as it stands. One possibility is that a part of the zeta-potential offset is due to us not using the most appropriate electric permittivity values in the model.
However, more research needs to be carried out to understand how to obtain a more appropriate value for this parameter.

The model shows that the streaming-potential coefficient is sensitive to changes in the electrochemical parameters that describe the rock/fluid interface, such as $\Gamma_{s}^{\circ}, p K_{M e}$ and $p K_{(-)}$, and to a lesser extent $\chi_{\zeta}$ at high salinity. Surface conductance parameters only have an effect at low salinity, and combine with the parameters that describe the rock microstructure (grain size, porosity, cementation exponent and formation factor) to control the flattening in the streaming-potential coefficient curve at low salinity, while having no effect at high salinity.

The model is extremely sensitive to the $\mathrm{pH}$ of the pore fluid, and hence we recommend that experimentalists ensure that the $\mathrm{pH}$ of their pore fluids are measured continually as they exit the sample during measurements, and that the $\mathrm{pH}$ is always quoted together with the electrical conductivity of the sample, the streamingpotential coefficient and the derived zeta potential.

Clearly, further work should be carried out to improve the fit of the theoretical model for the streaming-potential coefficient to the measured data. However, the present model seems to be a good beginning because no theoretical model previously existed. Improved experimental values for the electrochemical parameters would ensure that the model can be used with more confidence, while increased database of streaming-potential coefficient and zetapotential measurements as a function of $\mathrm{pH}$, salinity, and temperature would allow the model to be fitted to data with well-defined input parameters.

\section{ACKNOWLEDGMENTS}

This work has been made possible thanks to funding by the Natural Sciences and Engineering Research Council of Canada (NSERC) Discovery Grant Programme. We would also like to thank Mohd Jaafar and Jan Vinogradov who contributed to providing the experimental database.

\section{APPENDIX A \\ SOLUTION OF THE pH EQUATION}

The cubic $\mathrm{pH}$ equation given as equation 12 can be solved using the Tartaglia-Cardano approach (Cardano, 1545). A general cubic equation can be written as

$$
x^{3}+c_{1} x^{2}+c_{2} x+c_{3}=0
$$

The quadratic term in A-2 can be eliminated by letting

$$
\begin{gathered}
x=y-\frac{c_{1}}{3}, \quad A=\frac{\left(3 c_{2}-c_{1}^{2}\right)}{3}, \\
B=\frac{\left(2 c_{1}^{3}-9 c_{1} c_{2}+27 c_{3}\right)}{27},
\end{gathered}
$$

which gives

$$
y^{3}+A y^{2}+B=0
$$

The solution to equation A-3 then depends upon the sign of the discriminant $D$, where 


$$
D=\frac{A^{3}}{27}+\frac{B^{2}}{4}
$$

For $D>0$, equation A-3 has one real root and two imaginary roots, which are given by

$$
\begin{aligned}
y_{1}= & \left(-\frac{B}{2}+\sqrt{D}\right)^{1 / 3}+\left(-\frac{B}{2}-\sqrt{D}\right)^{1 / 3}, \\
y_{2}= & -\frac{1}{2}\left(\left(-\frac{B}{2}+\sqrt{D}\right)^{1 / 3}+\left(-\frac{B}{2}-\sqrt{D}\right)^{1 / 3}\right) \\
& +\frac{\sqrt{3} i}{2}\left(\left(-\frac{B}{2}+\sqrt{D}\right)^{1 / 3}-\left(-\frac{B}{2}-\sqrt{D}\right)^{1 / 3}\right), \\
y_{3}= & -\frac{1}{2}\left(\left(-\frac{B}{2}+\sqrt{D}\right)^{1 / 3}+\left(-\frac{B}{2}-\sqrt{D}\right)^{1 / 3}\right) \\
& -\frac{\sqrt{3} i}{2}\left(\left(-\frac{B}{2}+\sqrt{D}\right)^{1 / 3}-\left(-\frac{B}{2}-\sqrt{D}\right)^{1 / 3}\right) .
\end{aligned}
$$

For $D=0$, there are three real roots and at least two are equal. Because both $A$ and $B$ can be positive as well as negative, $D$ can become zero either by $A$ and $B$ simultaneously becoming zero, or when $A^{3} / 27=B^{2} / 4$. When $A$ and $B$ are both zero, there are three equal roots. The three real roots are given by

$$
\begin{gathered}
y_{1}=\left(-\frac{B}{2}+\sqrt{D}\right)^{1 / 3}+\left(-\frac{B}{2}-\sqrt{D}\right)^{1 / 3}, \\
y_{2}=y_{3}=-\frac{1}{2}\left(\left(-\frac{B}{2}+\sqrt{D}\right)^{1 / 3}+\left(-\frac{B}{2}-\sqrt{D}\right)^{1 / 3}\right) .
\end{gathered}
$$

For $D<0$, there are three, distinct, real roots which are given by

$$
y_{i}=2 \sqrt{-\frac{A}{3}} \cos \left(\cos ^{-1}\left( \pm \sqrt{-\frac{27 B^{2}}{4 A^{3}}}\right)+\frac{2 \pi k_{i}}{3}\right),
$$

where $i$ takes the values 1,2 , and $3, k_{i}=i-1$, and the minus sign applies when $B>0$, and the plus sign applies when $B<0$. The roots $x_{i}$ of A-1 can then be found by applying equation A-2 $\left(x=y-c_{1} / 3\right)$ to the individual roots. In the present application $c_{1}=\Delta C, c_{2}=-\left(K_{w}+K_{1}\right)$, and $c_{3}=2 K_{1} K_{2}$.

\section{REFERENCES}

Aizawa, K., R. Yoshimura, N. Oshiman, K. Yamazaki, T. Uto, Y. Ogawa, S B. Tank, W. Kanda, S. Sakanaka, Y. Furukawa, T. Hashimoto, M. Uyeshima, T. Ogawa, I. Shiozaki, and A. W. Hurst, 2005, Hydrothermal system beneath Mt. Fuji volcano inferred from magnetotellurics and electric self-potential: Earth and Planetary Science Letters, 235, 343-355, doi: 10.1016/j.eps1.2005.03.023.

Alkafeef, S. F., and A. F. Alajmi, 2006, Streaming potentials and conductivities of reservoir rock cores in aqueous and non-aqueous liquids: Colloids and Surfaces, A, 289, 141-148, doi: 10.1016/j.colsurfa.2006 .04 .023 .
Alkafeef, S. F., and A. F. Alajmi, 2007, The electrical conductivity and surface conduction of consolidated rock cores: Journal of Colloid and Interface Science, 309, 253-261, doi:10.1016/j.jcis.2007.02.004.

Allègre, V., L. Jouniaux, F. Lehmann, and P. Sailhac, 2010, Streaming potential dependence on water-content in Fontainebleau sand: Geophysica Journal International, 182, 1248-1266, doi: 10.1111/j.1365-246X.2010 .04716.x.

Antraygues, P., and M. Aubert, 1993, Self potential generated by two-phase flow in a porous medium: Experimental study and volcanological applications: Journal of Geophysical Research B, 98, 22273-22281.

Avena, M. J., and C. P. de Pauli, 1998, Proton adsorption and electrokinetics of an Argentinean montmorillonite: Journal of Colloid and Interface Science, 202, 195-204, doi: 10.1006/jcis.1998.5402.

Block, G. I., and J. G. Harris, 2006, Conductivity dependence of seismoelectric wave phenomena in fluid-saturated sediments: Journal of Geophysical Research, 111, B01304, doi:10.1029/2005JB003798.

Bolève, A., A. Crespy, A. Revil, F. Janod, and J. L. Mattiuzzo, 2007, Streaming potentials of granular media: Influence of the Dukhin and Reynolds numbers: Journal of Geophysical Research, 112, B08204, doi:10.1029/ 2006JB004673.

Booth, F., 1951, The dielectric constant of water and the saturation effect: Journal of Chemical Physics, 19, 391-394, doi: 10.1063/ 1.1748233

Cardano, G., 1545, Artis magnæ, sive de regulis algebraicis liber unus: Johannes Petreius.

Corwin, R. F., G. T. De Moully, R. S. Hardine, and H. F. Morrison, 1981, Interpretation of self-potential survey results from the East Mesa 1geothermal field, California: Journal of Geophysical Research B, 86, 1841-1848.

Crespy, A., A. Bolève, and A. Revil2007Influence of the Dukhin and Reynolds numbers on the apparent zeta potential of granular porous media: Journal of Colloid and Interface Science, 305, 188-194, doi: 10.1016/ j.jcis.2006.09.038.

Crow, D. R., 1988, Principles and applications of electrochemistry: Chapman and Hall.

Darnet, M., A. Maineult, and G. Marquis, 2004, On the origins of selfpotential (SP) anomalies induced by water injections into geothermal reservoirs: Geophysical Research Letters, 31, L19609, doi: 10.1029/ 2004GL020922.

Darnet, M., and G. Marquis, 2004, Modelling streaming potential (SP) signals induced by water movement in the vadose zone: Journal of Hydrology, 285, 114-124, doi: 10.1016/j.jhydrol.2003.08.010.

Di Maio, R., and D. Patella, 1991, Basic theory of electrokinetic effects associated with earthquakes: Bolletino di Geofisica Teorica e Applicata, 33, 130-131.

Dove, P. M., and J. D. Rimstidt, 1994, Silica-water interactions: Reviews in Mineralogy and Geochemistry, 29, 259-308.

Dupuis, J. C., and K. Butler, 2006, Vertical seismoelectric profiling in a borehole penetrating glaciofluvial sediments: Geophysical Research Letters, 33, L16301, doi: 10.1029/2006GL026385.

Dupuis, J. C., K. Butler, A. Kepic, and B. Harris, 2009, Anatomy of a seismoelectric conversion: Measurements and conceptual modeling in boreholes penetrating a sandy aquifer: Journal of Geophysical Research B, 114, B10306.

Dupuis, J. C., K. Butler, and A. W. Kepic, 2007, Seismoelectric imaging of the vadose zone of a sand aquifer: Geophysics, 72, no. 6, A81-A85, doi $10.1190 / 1.2773780$.

Fagerlund, F., and G. Heinson, 2003, Detecting sub-surface groundwater flow in fractured rock using self-potential (SP) methods: Environmental Geology, 43, 782-794.

Gaudin, A. M., and D. W. Fuerstenau, 1955, Streaming potential studies Quartz flotation with anionic collectors: Transactions of the American Institute of Mining and Metallurgical Engineers, 202, 66-72.

Glover, P. W. J., 2009, What is the cementation exponent? A new interpretation: The Leading Edge, 82-85, doi: 10.1190/1.3064150.

Glover, P. W. J., and N. Déry, 2010, Dependence of streaming potential on grain diameter and pore radius for quartz glass beads: Geophysics, 75, no. 6, F225-F241, doi: 10.1190/1.3509465.

Glover, P. W. J., and M. D. Jackson, 2010, Borehole electrokinetics: The Leading Edge, 29, 724-728, doi: 10.1190/1.3447786.

Glover, P. W. J., I. I. Zadjali, and K. A. Frew, 2006, Permeability prediction from MICP and NMR data using an electrokinetic approach: Geophysics, 71, no. 4, F49-F60, doi: 10.1190/1.2216930.

Grahame, D. C., 1950, Effects of dielectric saturation upon the diffuse double layer and free energy of hydration of ions: Journal of Chemical Physics, 18, 903-909, doi: 10.1063/1.1747807.

Guichet, X., L. Jouniaux, and J. P. Pozzi, 2003, Streaming potential of a sand column in partial saturation conditions: Journal of Geophysical Research, 108, B3, 2141, doi: 10.1029/2001JB001517.

Haines, S. S., S. R. Pride, S. L. Klemperer, and B. Biondi, 2007, Seismoelectric imaging of shallow targets: Geophysics, 72, no. 2, G9-G20, doi: $10.1190 / 1.2428267$. 
Hiemstra, T., and W. H. Van Riemsdijk, 1990, Multiple activated complex dissolution of metal (hydr)oxyde: A thermodynamic approach applied to quartz: Journal of Colloid and Interface Science, 136, 132-150, doi: 10.1016/0021-9797(90)90084-2.

Hunter, R. J., 1966, The interpretation of electrokinetic potentials: Journal of Colloid and Interface Science, 22, 231-239, doi: 10.1016/0021-9797(66) 90028-2.

Hunter, R. J., 1981, Zeta potential in colloid science: Academic Press

Iglesias, T. P., and J. Péon Fernandez, 2001, A mixing rule for the permittivity of binary mixtures in a framework of a weak-fluctuations model: Journal of Materials Science Letters, 20, 1333-1334, doi: 10.1023/A: 1010962920679.

Iler, R. K., 1979, The chemistry of silica: Wiley.

Ingham, M. R., H. M. Bibby, W. Heise, K. A. Jones, P. Cairns, S. Dravitzki, S. L. Bennie, T. G. Caldwell, and Y. A. Ogawa, 2009, Magnetotelluric study of Mount Ruapehu volcano, New Zealand: Geophysical Journal International, 179, 887-904, doi: 10.1111/gji.2009.179.issue-2.

Ishido, T., and H. Mizutani, 1981, Experimental and theoretical basis of electrokinetic phenomena in rock-water systems and its applications to geophysics: Journal of Geophysical Research B, 86, 1763-1775.

Ishido, T., and J. W. Pritchett, 1999, Numerical simulation of electrokinetic potentials associated with subsurface fluid flow: Journal of Geophysical Research B, 104, 15,247-15,259.

Jaafar, M. Z., J. Vinogradov, and M. D. Jackson, 2009, Measurement of streaming potential coupling coefficient in sandstones saturated with high salinity NaCl brine: Geophysical Research Letters, 36, L21306, doi: 10.1029/2009GL040549.

Jednacak, J., V. Pravdic, and W. Haller, 1974, The electrokinetic potential of glasses in aqueous electrolyte solutions: Journal of Colloid and Interface Science, 49, 16-23, doi: 10.1016/0021-9797(74)90293-8.

Jiang, Y. G., F. K. Shan, H. M. Jin, and L. W. Zhou, 1998, A method for measuring electrokinetic coefficients of porous media and its potential application in hydrocarbon exploration: Geophysical Research Letters, 25, 1581-1584, doi:10.1029/98GL01102.

Johnson, D. L., J. Koplik, and R. Dashen, 1987, Theory of dynamic permeability in fluid saturated porous media: Journal of Fluid Mechanics, 176, 379-402, doi: 10.1017/S0022112087000727.

Jørgensen, S. S., and A. T. Jensen, 1967, Acid-base properties of quartz suspensions: Journal of Physical Chemistry, 71, 745-750, doi: 10.1021/ j100862a040.

Jouniaux, L., M.-L. Bernard, M. Zamora, and J.-P. Pozzi, 2000, Streaming potential in volcanic rocks from Mount Pelée: Journal of Geophysical Research, 105, 8391-8401, doi: 10.1029/1999JB900435.

Jouniaux, L., and J. P. Pozzi, 1995a, Streaming potential and permeability of saturated sandstones under triaxial stress: Consequences for electrotelluric anomalies prior to earthquakes: Journal of Geophysical Research, 100, 10,197-10,209, doi: 10.1029/95JB00069.

Jouniaux, L., and J. P. Pozzi, 1995b, Permeability dependence of streaming potential in rocks forvarious fluid conductivities: Geophysical Research Letters, 22, 485-488, doi: 10.1029/94GL03307.

Jouniaux, L., and J. P. Pozzi, 1997, Laboratory measurements anomalous $0.1-0.5 \mathrm{~Hz}$ streaming potential under geochemical changes: Implications for electrotelluric precursors to earthquakes: Journal of Geophysical Research, 102, 15335-15343, doi: 10.1029/97JB00955.

Kirby, B. J., and E. F. Hasselbrink, 2004, Zeta potential of microfluidic substrates. 1. Theory, experimental techniques, and effects on separations: Electrophoresis, 25, 187-202, doi: 10.1002/(ISSN)1522-2683.

Kosmulski, M. 1996, Adsorption of cadmium on alumina and silica: Analysis of the values of stability constants of surface complexes calculated for different parameters of triple layer model: Colloids and Surfaces, A: Physicocemical and Engineering Aspects, 117, 201-214, doi: 10.1016/ 0927-7757(96)03706-5.

Kosmulski, M., and P. Dahlsten, 2006, High ionic strength electrokinetics of clay minerals: Colloids and Surfaces, A: Physicocemical and Engineering Aspects, 291, 212-218, doi: 10.1016/j.colsurfa.2006.06.037.

Kosmulski, M., E. Mączka, W. Janusz, and J. B. Rosenholm, 2002, Multi-instrument study of the electrophoretic mobility of quartz: Journal of Colloid and Interface Science, 250, 99-103, doi: 10.1006/jcis.2002 .8330 .

Li, H. C., and P. L. de Bruyn, 1966, Electrokinetic and adsorption studies on quartz: Surface Science, 5, 203-220, doi: 10.1016/0039-6028(66) 90082-3.

Li, S. X., D. B. Pengra, and P. Z. Wong, 1995, Onsager's reciprocal relation and the hydraulic permeability of porous media: Physical Review E (Statistical Physics, Plasmas, Fluids, and Related Interdisciplinary Topics), 51, 5748-5751, doi: 10.1103/PhysRevE.51.5748.

Lide, D. R., 2009, Handbook of chemistry and physics, 90th ed.: CRC Press.

Lorne, B., F. Perrier, and J.-P. Avouac, 1999, Streaming potential measurements 1. Properties of the electrical double layer from crushed rock samples: Journal of Geophysical Research, 104, 17857-17877, doi: 10 1029/1999JB900156.
Lyklema, J., and J. T. G. Overbeek, 1961, On the interpretation of electrokinetic potentials: Journal of Colloid and Interface Science, 16, 501-512.

Maineult, A., Y. Bernabé, and P. Ackerer, 2004, Electrical response of flow, diffusion, and advection in a laboratory sand box: Vadose Zone Journal, 3 $1180-1192$.

Mizutani, H., T. Ishido, T. Yokokura, and S. Ohnishi, 1976, Electrokinetic phenomena associated with earthquakes: Geophysical Research Letters, 3, 365-368, doi: 10.1029/GL003i007p00365.

Morgan, F. D., E. R. Williams, and T. R. Madden, 1989, Streaming potential properties of westerly granite with applications: Journal of Geophysical Research, 94, 12449-12461, doi: 10.1029/ JB094iB09p12449.

Naudet, V., A. Revil, E. Rizzo, J.-Y. Bottero, and P. Bégassat, 2004, Groundwater redox conditions and conductivity in a contaminant plume from geoelectrical investigations: Hydrology and Earth System Sciences, 8 8-22, doi: 10.5194/hess-8-8-2004.

O'Konski, C. T., 1960, Electric properties of macromolecules, V: Theory of ionic polarization in polyelectrolytes: Journal of Physical Chemistry, 64, 605-619, doi: 10.1021/j100834a023.

Overbeek, J. T. G., 1952, Electrochemistry of the double layer, in H. R. Kruyt, ed., Colloid science 1, Irreversible systems: Elsevier, 115-193.

Park, J., and J. R. Regalbuto, 1995, A simple, accurate determination of oxide PZC and the strong buffering effect of oxide surfaces at incipient wetness: Journal of Colloid and Interface Science, 175, 239-252, doi: 10.1006/jcis.1995.1452

Pengra, D. B., S. X. Li, and P. Z. Wong, 1999, Determination of rock properties by low-frequency AC electrokinetics: Journal of Geophysical Research, 104, 29485-29508, doi: 10.1029/1999JB900277.

Perrier, F., M. Trique, J. Aupiais, U. Gautam, and P. Shrestha, 1999, Electric potential variations associated with periodic spring discharge in western Nepal: Comptes Rendus de l'Academie des Sciences Series IIA Earth and Planetary Science, 328, 73-79.

Phillips, S. L., H. Ozbek, and R. J. Otto, 1978, Basic energy properties of electrolytic solutions database: paper presented at Sixth International CODATA Conference, 2-25, accessed 10 June 2010, http://www.etde.org/ etdeweb/purl.cover.jsp?purl=/6628103-xaRVpW/.

Poirier, J. E., and J. M. Cases, 1985, Sur l'origine et la nature de l'interaction adsorbat-adsorbant dans les systèmes à interactions faibles, in Solid-liquid interactions in porous media; Technip Editions, 447-462.

Pride, S., 1994, Governing equations for the coupled electromagnetics and acoustics of porous media: Physical Review B: Condensed Matter and Materials Physics, 50, 15678-15696, doi: 10.1103/PhysRevB.50 15678 .

Pride, S. R., and F. D. Morgan, 1991, Electrokinetic dissipation induced by seismic waves: Geophysics, 56, 914-925, doi: 10.1190/1.1443125.

Probstein, R. F., and R. E. Hicks, 1993, Removal of contaminants from soils by electric fields: Science, 260, 498-503, doi: 10.1126/science.260.5107 498.

Reppert, P., and F. Morgan, 2003a, Temperature dependent streaming potentials: 1. Theory: Journal of Geophysical Research, 108, 2546, doi: 10.1029/2002JB001754.

Reppert, P., and F. Morgan, 2003b, Temperature dependent streaming potentials: 2. Laboratory: Journal of Geophysical Research, 108, 2547, doi: $10.1029 / 2002 J B 001755$.

Revil, A., 2002, Comment on "Rapid fluid disruption: A source for selfpotential anomalies on volcanoes," by M. J. S. Johnston, J. D. Byerlee, and D. Lockner: Journal of Geophysical Research, 107, B8, 2155, doi: 10 1029/2001JB000788.

Revil, A., and L. M. Cathles, 1999, Permeability of shaly sands: Water Resources Research, 35, 651-662, doi: 10.1029/98WR02700.

Revil, A., L. M. Cathles, S. Losh, and J. A. Nunn, 1998, Electrical conductivity in shaly sands with geophysical applications: Journal of Geophysical Research, 103, 23925-23936, doi: 10.1029/98JB02125.

Revil, A., and A. Cerepi, 2004, Streaming potentials in two-phase flow conditions: Geophysical Research Letters, 31, L11605, doi: 10.1029/ 2004GL020140.

Revil, A., and P. W. J. Glover, 1997, Theory of ionic surface electrical conduction in porous media: Physical Review B: Condensed Matter and Materials Physics, 55, 1757-1773, doi: 10.1103/PhysRevB 55.1757.

Revil, A., and P. W. J. Glover, 1998, Nature of surface electrical conductivity in natural sands, sandstones, and clays: Geophysical Research Letters, 25, 691-694, doi: 10.1029/98GL00296.

Revil, A., D. Hermitte, E. Spangenberg, and J. J. Cochemé, 2002, Electrical properties of zeolitized volcaniclastic materials: Journal of Geophysical Research, 107, B8, 2168, doi: 10.1029/2001JB000599.

Revil, A., and P. Leroy, 2001, Hydroelectric coupling of clayey material: Geophysical Research Letters, 28, 1643-1646, doi: 10.1029/ 2000 GL012268. 
Revil, A., P. A. Pezard, and P. W. J. Glover, 1999a, Streaming potential in porous media. I. Theory of the zeta-potential: Journal of Geophysical Research, 104, B9, 20021-20031, doi: 10.1029/1999JB900089.

Revil, A., G. Saracco, and P. Labazuy, 2003, The volcano-electric effect Journal of Geophysical Research, 108, B5, 2251, doi: 10.1029/ 2002JB001835.

Revil, A., H. Schwaeger, L. M. Cathless, and P. D. Manhardt, 1999b, Streaming potential in porous media 2 . Theory and application to geothermal systems: Journal of Geophysical Research, 104, 20033-20048, doi: 10.1029/1999JB900090.

Rustad, J. R., E. Wasserman, A. R. Felmy, and C. Wilke, 1998, Molecular dynamics study of proton binding to silica surfaces: Journal of Colloid and Interface Science, 198, 119-129, doi: 10.1006/jcis.1997.5195.

Sailhac, P., and G. Marquis, 2001, Analytic potentials for the forward and inverse modeling of SP anomalies caused by subsurface fluid flow: Geophysical Research Letters, 28, 1851-1854, doi: 10.1029/ 2000 GL012457.

Saunders, J. H., M. D. Jackson, and C. C. Pain, 2008, Fluid flow monitoring in oil fields using downhole measurements of electrokinetic potential Geophysics, 73, no. 5, E165, doi: 10.1190/1.2959139.

Scales, P. J., F. Grieser, and T. W. Healy, 1990, Electrokinetics of the muscovite mica-aqueous interface: Langmuir, 6, 582-589, doi: 10.1021/ la00093a012.

Sen, P., and P. Goode, 1992a, Influence of temperature on electrical conductivity on shaly sands: Geophysics, 57, 89-96, doi: 10.1190/ 1.1443191.

Sen, P., and P. Goode, 1992b, Errata, to "Influence of temperature on electrical conductivity of shaly sands": Geophysics, 57, 89, doi: 10.1190/ 1.1443191

Shapiro, A. P., and R. F. Probstein, 1993, Removal of contaminants from saturated clay by electroosmosis: Environmental Science and Technology, 27, 283-291, doi: 10.1021/es00039a007.

Smith, A. L., 1976, Electrokinetics of the oxide - Solution interface: Journal of Colloid and Interface Science, 55, 525-530, doi: 10.1016/00219797(76)90062-X.

Sprunt, E. S., T. B. Mercer, and N. F. Djabbarah, 1994, Streaming potential from multiphase flow: Geophysics, 59, 707-711, doi: 10.1190/ 1.1443628 .

Svetov, B. S., S. D. Karinskij, I. Y. Kuksa, and V. I. Odintsov, 1997, Magnetotelluric monitoring of geodynamic processes: Annali di Geofisica, 40, 219-237.

Tadros, Th. F., and J. Lyklema, 1969, The electrical double layer on silica in the presence of bivalent counter-ions: Journal of Electroanalytical Chemistry and Interfacial Electrochemistry, 22, 1-7, doi: 10.1016/S0022-0728 (69)80140-3.
Tardif, E., P. W. J. Glover, and J. Ruel, 2011, Frequency-dependent streaming potential of Ottawa sand: Journal of Geophysical Research B, 116, B04206

Thompson, A., and G. Gist, 1993, Geophysical applications of electrokinetic conversion: The Leading Edge, 12, 1169-1173, doi: 10.1190/1.1436931.

Titov, K., A. Revil, P. Konasovsky, S. Straface, and S. Troisi, 2005, Numerical modeling of self-potential signals associated with a pumping test experiment: Geophysical Journal International, 162, 641-650, doi: 10 1111/gji.2005.162.issue-2.

Tosha, T., N. Matsushima, and T. Ishido, 2003, Zeta potential measured for an intact granite sample at temperatures to $200^{\circ} \mathrm{C}$ : Geophysical Research Letters, 30, 6, 1295, doi: 10.1029/2002GL016608.

Trique, M., F. Perrier, T. Froidefond, J. P. Avouac, and S. Hautot, 2002, Fluid flow near reservoir lakes inferred from the spatial and temporal analysis of the electric potential: Journal of Geophysical Research B, 107, 2239 .

van der Heyden, F. H. J., D. Stein, K. Besteman, S. G. Lemay, and C. Dekker, 2006, Charge inversion at high ionic strength studied by streaming currents: Physical Review Letters, 96, 224502, doi: 10.1103/PhysRevLett 96.224502 .

Vinogradov, J., M. Z. Jaafar, and M. D. Jackson, 2010, Measurement of streaming potential coupling coefficient in sandstones saturated with natural and artificial brines at high salinity: Journal of Geophysical Research, 115, B12204, doi: 10.1029/2010JB007593.

Walker, E., and P. W. J. Glover, 2010, Characteristic pore size, permeability and the electrokinetic coupling coefficient transition frequency in porous media: Geophysics, 75, no. 6, E235-E246, doi: 10.1190/1.3506561.

Watillon, A., and R. de Backer, 1970, Potentiel d'écoulement, courant d'écoulement et conductance de surface à l'interface eau-verre: Journal of Electroanalytical Chemistry, 25, 181-196.

Waxman, M. H., and L. J. M. Smits, 1968, Electrical conductivities in oil-bearing shaly sands: Society of Petroleum Engineers Journal, 8, 107-122, doi: 10.2118/1863-A.

Will, G., and G. Nover, 1986, Measurement of the frequency dependence of the electrical conductivity and some other petro-physical parameters of core samples from the Konzen (West Germany) drill hole: Annales Geophysicae, 4, B2, 173-182.

Wu, L., W. Forsling, and P. W. Schlindler, 1991, Surface complexation of calcium minerals in aqueous solution: Journal of Colloid and Interface Science, 147, 178-185, doi: 10.1016/0021-9797(91) 90145-X.

Yates, D. E., and T. W. Healy, 1976, The structure of the silica/electrolyte interface: Journal of Colloid and Interface Science, 55, 9-19, doi: 10.1016/0021-9797(76)90003-5. 